\title{
Damring Formation During Rotary Kiln Chromite Pre-reduction: Effects of Pulverized Carbonaceous Fuel Selection and Partial Pellet Melting
}

\author{
Y. VAN STADEN, J.P. BEUKES, P.G. VAN ZYL, E. RINGDALEN, M. TANGSTAD, \\ E.L.J. KLEYNHANS, and J.R. BUNT
}

\begin{abstract}
Electricity consumption is the largest cost contributing factor in the production of ferrochrome. Currently the pelletized chromite pre-reduction process (solid-state reduction of chromite) is the process option with the lowest specific electricity consumption $(\mathrm{MWh} /$ ton). In this process, pelletized chromite is fed into a rotary kiln at $1573 \mathrm{~K}\left(1300{ }^{\circ} \mathrm{C}\right)$, where partial pre-reduction takes place. Damring formation (material build-up) in the rotary kiln causes routine shutdowns, resulting in loss of revenue. The damring formation is possibly caused by melting of the ash of the pulverized coal used to fire the kiln and/or the partial melting of the chromite pellets. Ash fusion temperatures of twenty different samples were evaluated to assess the temperature at which the pulverized coal ash will start to contribute to damring formation. Sessile drop tests were used to assess the softening behavior of different ore types (e.g., UG2, MG, and LG metgrade), as well as softening of composite chromite pellets made from these ores. Actual damrings were also analyzed using scanning electron microscopy with energy dispersive X-ray spectroscopy. Results indicate that it is mainly the pulverized coal ash that will contribute to damring formation, and not ore or pellet softening. Multiple-linear regression was used to derive equations to predict the ash fusion temperatures of the pulverized coal ash, which can be used by ferrochrome producers to optimize pulverized coal selection.
\end{abstract}

https://doi.org/10.1007/s11663-018-1376-7

(C) The Author(s) 2018

\section{INTRODUCTION}

Chromite is a mineral with a spinel crystalline structure with the formula $\left[\left(\mathrm{Mg}, \mathrm{Fe}^{2+}\right)(\mathrm{Al}, \mathrm{Cr}\right.$, $\left.\left.\mathrm{Fe}^{3+}\right)_{2} \mathrm{O}_{4}\right]{ }^{[1]}$ Chromite is of great importance since it is the only commercially viable source of new chromium (Cr) units. ${ }^{[2,3]} \mathrm{Cr}$ has many applications in the metallurgical, chemical, and refractory fields. The application of importance in this study is the production of ferrochrome $(\mathrm{FeCr}) . \mathrm{FeCr}$ is an alloy used mainly in the production of stainless steel, which is a vital alloy in modern society. According to Rao, ${ }^{[4]}$ approximately 90 pct of all mined chromite is utilized in the production of $\mathrm{FeCr}$.

Y. VAN STADEN, J.P. BEUKES, P.G. VAN ZYL, E.L.J. KLEYNHANS, and J.R. BUNT are with the Chemical Resource Beneficiation, North-West University, Potchefstroom, Private Bag X6001, Potchefstroom, 2520, South Africa. Contact e-mail: paul.beukes@nwu.ac.za E. RINGDALEN is with the Sintef, Materials and Chemistry, 7465 Trondheim, Norway. M. TANGSTAD is with the Norweigian University of Science and Technology (NTNU), 7465 Trondheim, Norway.

Manuscript submitted November 23, 2017.

Article published online August 7, 2018.
The single largest cost component in $\mathrm{FeCr}$ production is electricity consumption. ${ }^{[5,6]}$ It is therefore important for $\mathrm{FeCr}$ producers to apply processes to minimize energy use. Several of these processes have been developed. ${ }^{[7-9]}$ One of these processes, known as Chrome Direct Reduction (CDR), was commercialized in South Africa in the late 1980s and entailed the direct reduction (which is complete or almost complete pre-reduction) of fine chromite ores. ${ }^{[9]}$ However, due to operational difficulties, the process was abandoned fairly quickly. Another process implemented commercially was developed by Showa Denko in the 1970s, i.e., solid-state reduction of chromite (SRC) or otherwise known as pelletized chromite pre-reduction. This process was modified and is being applied by Glencore Alloys at two very large smelters in South Africa (Lydenburg operations and the Lion Ferrochrome smelter). ${ }^{[10]} \mathrm{FeCr}$ smelters applying this process have also relatively recently been developed in China, but information regarding these smelters is not yet available in the public peer-reviewed domain. Glencore Alloys refer to their application of pelletized chromite pre-reduction as the Premus process. ${ }^{[10]}$ This process has the lowest energy consumption (specific electricity 
consumption (SEC), i.e., $\mathrm{MWh} /$ ton $\mathrm{FeCr}$ ), high $\mathrm{Cr}$ recovery, as well as being more environmentally friendly than the conventional process in some respects. ${ }^{[10]}$

In the pelletized chromite pre-reduction process, raw materials (chromite ore, reductants, and clay binder) are dry milled, pelletized, and pre-heated, after which the pellets are fed into a counter current rotary kiln where chromite pre-reduction takes place. These hot, pre-reduced pellets are then fed directly into a closed submerged arc furnace (SAF), with the required fluxes and reductants. Feeding the hot, pre-reduced pellets into the SAF reduces the amount of energy required for smelting. ${ }^{[10,11]}$ The pre-reduction achieved relates to metallization of up to 90 pet for iron $(\mathrm{Fe})$ and 50 pet for $\mathrm{Cr}$, and results in reduced SEC during the smelting process by up to 40 pct. ${ }^{[9]}$ Other advantages associated with the pelletized chromite pre-reduction process include the consumption of fine chromite ores and reductants, significant replacement of coke with less expensive reductants such as anthracite, as well as the production of a low silicon ( $\mathrm{Si}$ )- and sulfur (S)-containing $\mathrm{FeCr}$ product. ${ }^{[8,10]}$ Disadvantages associated with this process are the higher capital $\operatorname{cost}^{[10]}$ and the extensive operational control that is required due to the variation in pre-reduction levels and carbon $(\mathrm{C})$ contents of the pre-reduced pelletized furnace feed material. ${ }^{[12]}$

Previous studies related to chromite pre-reduction focused on aspects such as the fundamental reaction mechanism $\mathrm{s}^{[8]}$ and enhancing pre-reduction by the use of different conditions and/or additives. ${ }^{[13-16]}$ Kleynhans et al..$^{[17,18]}$ also investigated the effect of different clay binders and carbonaceous reductants.

Chromite pre-reduction applied on an industrial scale takes place in a counter current rotary kiln. Pellets are fed into the kiln and heated to approximately $1573 \mathrm{~K}$ $\left(1300^{\circ} \mathrm{C}\right)$. Cross- and longitudinal sectional cut illustrations of a typical rotary kiln with pelletized feed that is used in the chromite pre-reduction process are presented in Figure 1.

During chromite pre-reduction, damrings (material build-up) are formed in the kiln (Figure 1). These damrings can have positive and/or negative impacts on the process. Limited damring formation can protect the refractory lining of the kiln. It is also known that limited damring formation in strategic areas (e.g., marked with "a" in Figure 1) can increase the retention time of the pellets in the kiln hot zone, therefore enhancing pre-reduction levels. However, if damring formation is too extensive, it compromises material throughput. Also, excessive damring formation in certain areas (e.g., marked with "b" in Figure 1) can actually increase the effective slope that the pelletized chromite pellets experience in the kiln, which will lead to shorter retention time and lower pre-reduction levels. Currently, routine shutdowns have to be performed on chromite pre-reduction kilns to break out the damrings in order to maintain the desired throughput. Figure 2 presents a photo taken during a recent shutdown of a chromite pre-reduction kiln, which clearly illustrates the extent of the problem.

One of the possible reasons for damring formation is melting of pulverized fuel (PF) coal ash that originates from the coal used to fire the kiln. Therefore, the ash fusion temperatures (AFTs) of the PF coal ash can be used as an indication of the temperature at which the ash will start to contribute to damring formation. AFTs, i.e., initial deformation $\left(T_{\text {indef }}\right)$, softening $\left(T_{\text {soft }}\right)$, hemispherical $\left(T_{\text {hem }}\right)$, and fluid temperature $\left(T_{\text {fluid }}\right)$, can be determined experimentally. ${ }^{[19]}$ However, AFTs are not always readily available, since AFT analyses are time-consuming and special instrumentation is needed. In contrast, proximate, ultimate, total $\mathrm{S}$, calorific value $(\mathrm{CV})$, and ash composition analyses are routinely conducted in industry. Therefore, there have been a number of studies done on the prediction of AFT based on chemical composition. Previously Liu et al. ${ }^{[20]}$ predicted AFT for steam boiler operations of power plants based on chemical composition. These authors used a neural network method, i.e., ACO-BP neural network based on ant colony optimization, to predict the AFT. Chakravarty et al. ${ }^{[21]}$ used thermodynamic modeling to predict and understand ash fusion behavior and Winegartner and Rhodes ${ }^{[22]}$ used regression analysis to calculate AFT of coal ash from chemical composition.
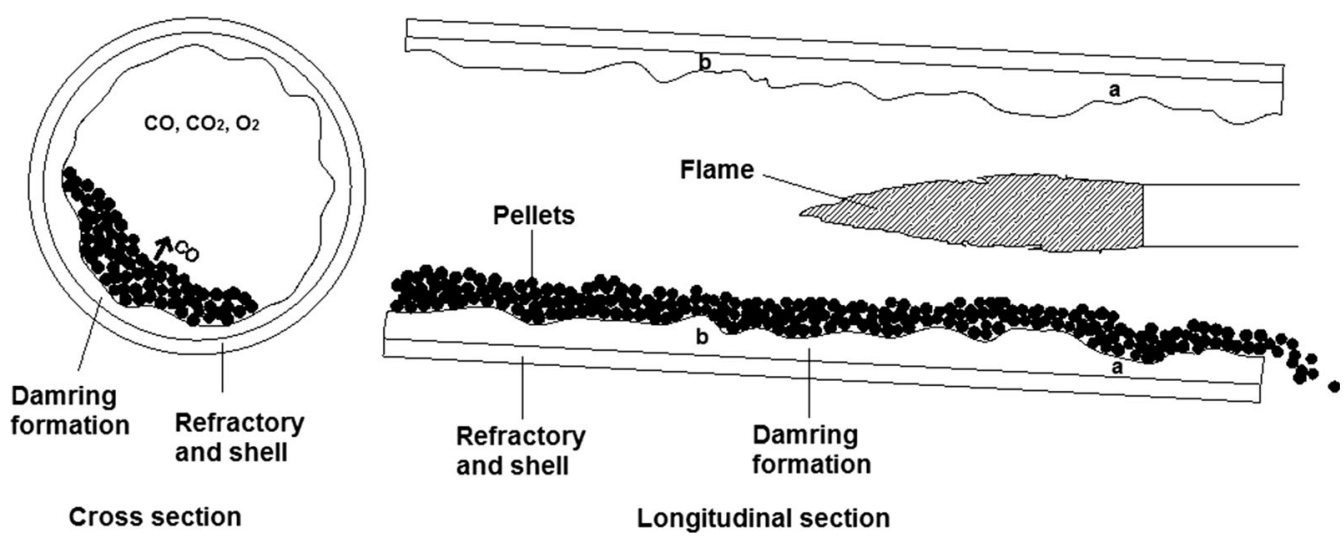

Longitudinal section

Fig. 1-Illustration of the cross and longitudinal sections of a rotary kiln used in pelletized chromite pre-reduction. 


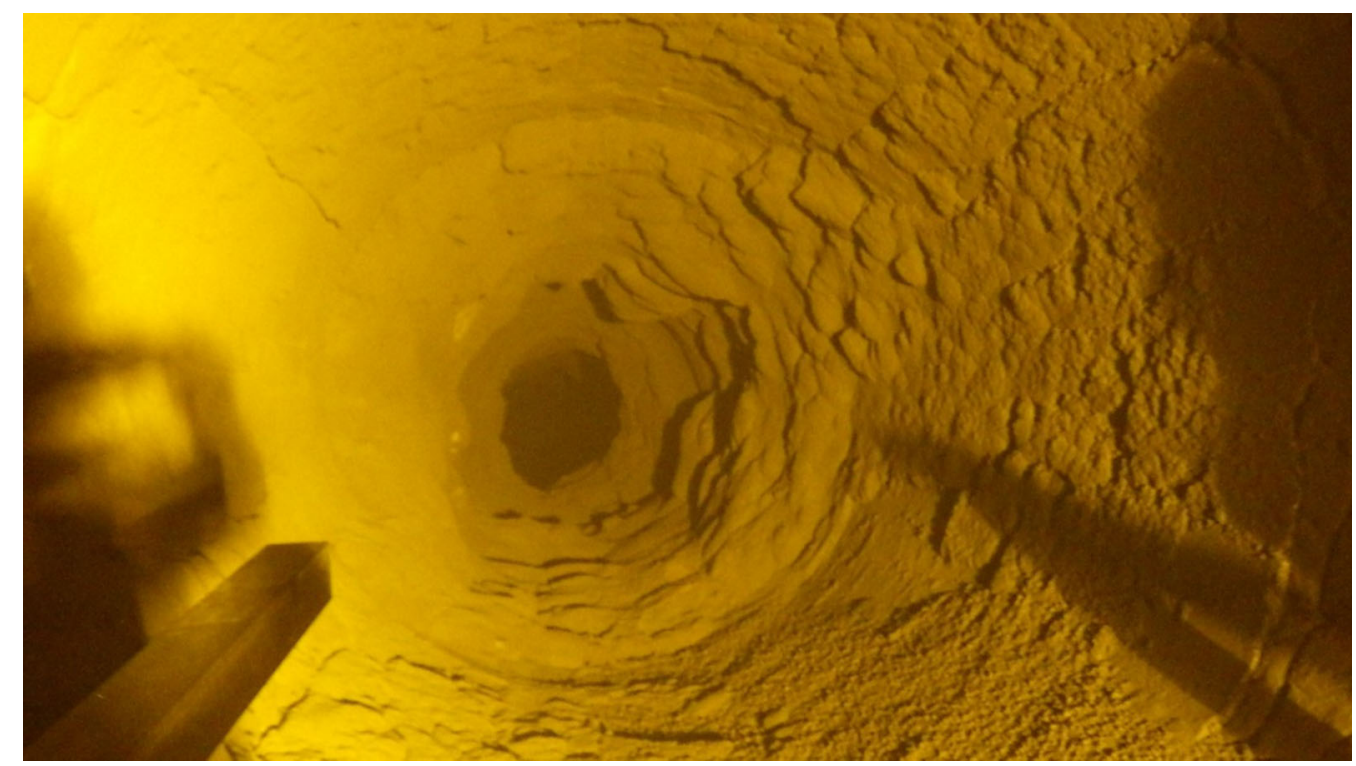

Fig. 2-A picture of damrings inside a pelletized chromite pre-reduction kiln.

The possibility exists that damring formation can also be caused by partial melting of pellets being fed into the kiln and/or pellet fragments formed in the kiln. Extensive sessile drop test work has been conducted for manganese ores, ${ }^{23-25]}$ in order to observe their behavior during heating. The sessile drop test is used to measure the melting and reduction temperatures of materials. ${ }^{[24]}$ As far as the authors could assess, no such work has been published for chromite ores.

In this paper, it is indicated how multiple-linear regression (MLR) analysis, using proximate, ultimate, total $\mathrm{S}, \mathrm{CV}$, and ash composition analyses as independent parameters, can be used to calculate the AFT of carbonaceous materials. The calculated AFT can be used by $\mathrm{FeCr}$ producers to select $\mathrm{PF}$ coals that will contribute less to damring formation, which will increase the kiln operational time between damring break-out shutdowns. This will enhance production output and improve profitability. The possible contribution of pellet softening to damring formation was also investigated, by using sessile drop tests to observe the melting behavior of the composite pellets and the individual pellet components.

\section{EXPERIMENTAL METHODS}

\section{A. Carbonaceous Materials and Characterization Thereof}

Although only coal (which is less expensive than, e.g., coke and anthracite) is currently used as PF to fire pre-reduction rotary kilns, a wider selection of materials was included in this study to assess if the developed method would be applicable for a wider selection of carbonaceous materials. These materials consisted out of twenty coals, anthracites, chars, and cokes. At the time when this research was initiated the afore-mentioned carbonaceous materials were either used as PF to fire the rotary kilns or as reductants in the composite pre-reduced pellets at $\mathrm{FeCr}$ producers applying the pelletized chromite pre-reduction process.

During the proximate analysis (air-dried basis), the inherent moisture content (MC) was determined according to SABS ISO 11722:1999 and was done by placing a $1 \mathrm{~g}$ sample in an air-oven at $378 \mathrm{~K}\left(105^{\circ} \mathrm{C}\right)$ for 1 hour until the mass remained constant. The ash content was determined according to SABS ISO 1171:2010 and it entailed heating $1 \mathrm{~g}$ of sample to $1088 \mathrm{~K} \pm 10 \mathrm{~K}$ $\left(815^{\circ} \mathrm{C} \pm 10^{\circ} \mathrm{C}\right)$ for at least 1.5 hours. The volatile matter (VM) content was determined according to SABS ISO 562:2010. In this method, the sample is heated in inert atmosphere at $1173 \mathrm{~K} \pm 10 \mathrm{~K}\left(900^{\circ} \mathrm{C} \pm\right.$ $10{ }^{\circ} \mathrm{C}$ ) for $7 \mathrm{~min}$. The pct mass fraction of $\mathrm{VM}$ is calculated from the loss in mass after deducting the loss of mass due to moisture. The fixed carbon (FC) was calculated by deducting the MC, ash content, and VM from the total weight.

The ultimate analysis was undertaken according to SABS ISO 29541:2010 in which the C, hydrogen $(\mathrm{H})$, nitrogen $(\mathrm{N})$, and oxygen $(\mathrm{O})$ contents were determined. The $\mathrm{C}$ and $\mathrm{H}$ contents were determined by heating the sample in a stream of $\mathrm{O}_{2}$ at $1623 \mathrm{~K}\left(1350{ }^{\circ} \mathrm{C}\right)$ and converting $\mathrm{C}$ and $\mathrm{H}$ into their corresponding gases, i.e., carbon dioxide and water. Magnesium perchlorate was used to absorb the water and sodium hydroxide to absorb the carbon dioxide, which was then determined gravimetrically. For the determination of $\mathrm{N}$, the sample was heated with concentrated sulfuric acid in the presence of a mixed catalyst to convert $\mathrm{N}$ into ammonium sulfate. The ammonia in the solution is then released using steam distillation after which it was absorbed in boric acid and the $\mathrm{N}$ was then determined by titration with sulfuric acid. The sum of these elements, i.e., $\mathrm{C}, \mathrm{H}$, and $\mathrm{N}$, together with the ash, and $\mathrm{MC}$, expressed as mass percentage, was used to calculate the $\mathrm{O}$ content (adding up to a total of 100). 
The determination of the total $\mathrm{S}$ content was done according to SABS ISO 197579:2006 using a LECO Sulfur analyzer. The sample was combusted at $1623 \mathrm{~K}$ $\left(1350{ }^{\circ} \mathrm{C}\right)$ in a stream of oxygen. Thereafter, particulates and water vapor are removed from the gas stream. The gas stream then passes through a cell in which sulfur dioxide is measured by an infrared absorption detector. The $\mathrm{S}$ in the sample is then calculated from the results.

The gross $\mathrm{CV}$ was determined (according to SABS ISO 1928:2009) by burning a sample of solid fuel in high-pressure oxygen in a bomb calorimeter. The gross $\mathrm{CV}$ is calculated from the corrected temperature rise and the effective heat capacity of the calorimeter. The ash composition was determined using X-ray fluorescence (XRF) as specified in ASTM D4326. For the afore-mentioned analysis, only contents above the detection limit of the various ash components were retained.

The samples used in the AFT determination were sized and ashed in the same method as described earlier, using SABS ISO 1171:2010, prior to the analysis. AFT tests were performed according to the SABS ISO 540:2008, which involves heating of a cone of the ash sample. Four different temperatures are then recorded according to the specific shape of the ash cone, i.e., the $T_{\text {indef }}$ when the corners of the cone first become rounded; $T_{\text {soft }}$ when the top of the cone first become rounded; $T_{\text {hem }}$ when the entire cone took on a hemispherical shape; and the $T_{\text {fluid }}$ when the cone collapsed to a flattened button on the furnace floor ${ }^{[19]}$ According to SABS ISO 540:2008, the standard deviation of AFTs measured in this manner is typically $\pm 30 \mathrm{~K}$.

AFT tests were conducted in both oxidizing (normal air) and reducing atmospheres $\left(\mathrm{CO} / \mathrm{CO}_{2}\right)$, since both atmospheres are relevant to chromite pre-reduction kilns. ${ }^{[17]}$ The atmosphere inside the kiln is partially oxidizing to allow PF combustion, while the high carbon content inside the pellets causes a partial positive $\mathrm{CO}$ pressure inside the pellets themselves, preventing oxygen from entering the pellets (therefore a reducing environment inside the pellets). ${ }^{[17]}$

\section{B. Computational Methods}

A simple linear regression model includes a constant $(c)$, an independent variable $(x)$, and a dependent variable $(y)$. The objective is then to establish the relationship between the independent $(x)$ and the dependent $(y)$ variables by fitting a linear equation to the data. In MLR, there is more than one independent variable $(x)$ and the relationship between the dependent variable (y) and the independent variables $(x)$ is given by the following equation. ${ }^{[26]}$

$$
y=c_{0}+c_{1} x_{1}+c_{2} x_{2}+\cdots \cdots c_{\mathrm{p}} x_{\mathrm{p}} .
$$

In this paper, the individual AFTs were considered as the dependent variable, while the proximate, ultimate, total $\mathrm{S}, \mathrm{CV}$, and the ash composition data as independent variables. The root mean squared error (RMSE) between the calculated independent variable and the experimental value was calculated to quantify the difference. ${ }^{[26-28]}$ Sixteen of the twenty samples were used in the MLR calculation, while the remaining four samples were used to assess how well the method performed.

SPSS programming software was used to calculate parameters that could be used to interpret the MLR results and to determine the contributions of the different independent variables to the calculated AFTs.

\section{Sessile Drop Analysis of Chromite, Composite Pellet Mixtures, and Pellet Components}

The maximum temperature of the AFT test instrument was $1823 \mathrm{~K}\left(1550{ }^{\circ} \mathrm{C}\right)$. Due to the spinel crystalline structure of chromite, the melting temperature thereof is higher than the afore-mentioned temperature. Therefore in order to determine the temperatures at which softening of the ores, or ore mixtures took place, an alternative method, i.e., sessile drop, was used. The sessile drop furnace has a maximum operating temperature of $2673 \mathrm{~K}\left(2400{ }^{\circ} \mathrm{C}\right) .{ }^{[23-25]}$

For the sessile drop study, seven typical metallurgical grade ores were obtained from $\mathrm{FeCr}$ producers across South Africa. Since more than a quarter of chromite consumed by the $\mathrm{FeCr}$ industry outside South Africa originate from South Africa, ${ }^{[29]}$ results obtained from these ores will also be of international relevance. The afore-mentioned ores were individually mixed with a carbonaceous reductant and a clay binder to form pellet mixtures, as industrially applied. ${ }^{[17]}$ Anthracite breeze from Nkomati Anthracite (Pty) Ltd $^{[30]}$ was used as the reductant in the mixtures and bentonite clay as the binder. Both these materials were previously characterized $^{[17]}$ and such details are therefore not repeated here. The softening temperatures of the anthracite breeze and the bentonite clay were also investigated individually, using the sessile drop test method.

The chromite ore samples were dry milled to the particle size applied in the pre-reduction process, i.e., 90 pct smaller than $75 \mu \mathrm{m}\left(d_{90}=75 \mu \mathrm{m}\right)$. A Siebtechnik laboratory disc mill with a tungsten carbide grinding chamber was used, to avoid possible iron contamination. The particle size distribution was determined using a Malvern Mastersizer 2000. Each pellet mixture consisted of $3 \mathrm{wt}$ pct clay, $\sim 20 \mathrm{wt}$ pct anthracite (to ensure 15 wt pct FC content), and the remainder was made up with chromite ore. These pellet mixtures were also dry milled to the same particle size as previously indicated for the ores $\left(d_{90}=75 \mu \mathrm{m}\right)$.

The above-mentioned milled samples were pressed into small pellets of approximately $3 \mathrm{~mm}$ in diameter and height. An investigated pellet was placed on a graphite substrate disk (diameter of $10 \mathrm{~mm}$ and height of $3 \mathrm{~mm}$ ), which was then placed in the sample holder in the sessile drop furnace. The furnace was heated at $300 \mathrm{~K} / \mathrm{min}\left(300{ }^{\circ} \mathrm{C} / \mathrm{min}\right)$ up to $1173 \mathrm{~K}\left(900{ }^{\circ} \mathrm{C}\right)$ and then at $10 \mathrm{~K} / \mathrm{min}\left(10{ }^{\circ} \mathrm{C} / \mathrm{min}\right)$ up to $2223 \mathrm{~K}\left(1950{ }^{\circ} \mathrm{C}\right)$. The furnace was continuously purged with $0.5 \mathrm{Nl} / \mathrm{min}$ of carbon monoxide for the entire duration of the experiment. A firewire digital video camera with a telocentric zoom lens was used to record images at a resolution of 


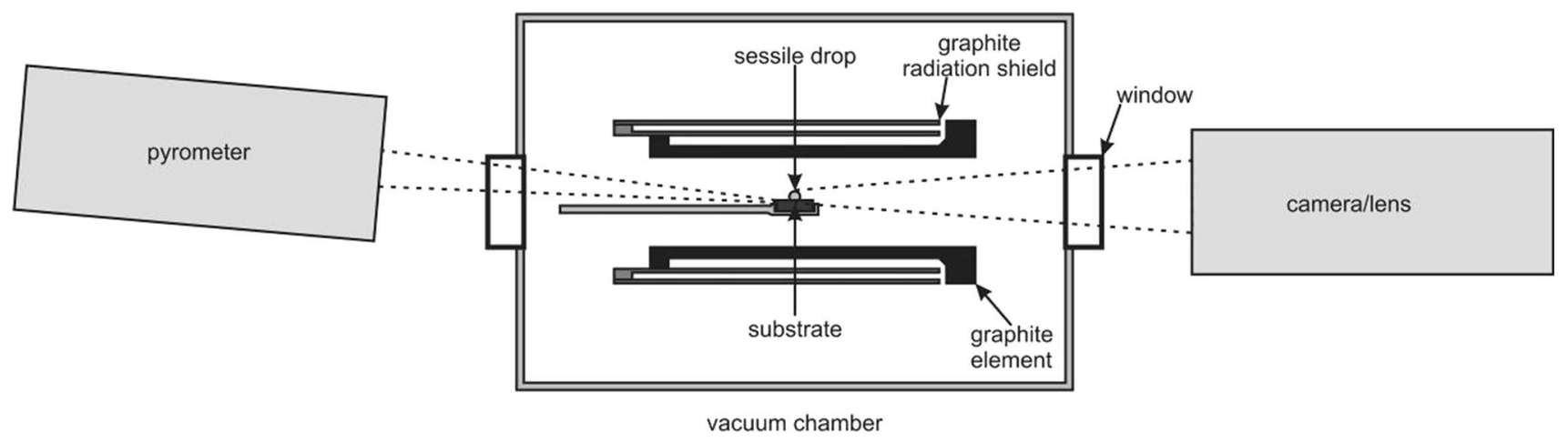

Fig. 3-A schematic of the sessile drop furnace Reprinted from Refs. [24] and [25]

$1280 \times 960$ pixels, to determine the different stages of melting. Figure 3 presents an illustration of the sessile drop furnace.

\section{Surface Analysis of Actual Damrings}

Actual damrings broken out during a kiln shutdown were obtained from a South African ferrochrome smelter applying the pelletized chromite pre-reduction process. Several pieces of the damrings were polished and analyzed with a FEI Quanta 200 scanning electron microscope (SEM) with an integrated Oxford Instruments INCA 200 energy dispersive X-ray spectroscopy (EDS) microanalysis system.

\section{RESULTS AND DISCUSSION}

\section{A. Carbonaceous Material Characterizations}

Table I presents the proximate- and ultimate analyses, total $\mathrm{S}$ contents, CVs, ash compositions, as well as the reducing and oxidizing AFTs of all the carbonaceous materials considered. Obviously, elements occurring in the ash could occur in a different phase than what is presented; however, the reported species are standard for this type of analysis.

As expected, the coal samples had the lowest FC and highest VM content, while the char samples had the highest ash contents. There are many factors influencing the melting point of carbonaceous materials; hence, it is difficult to relate the measured parameters directly to AFTs. However, some authors have made general observations. Van Dyk and Keyser, ${ }^{[31]}$ found that low ash melting temperatures were generally accompanied by high $\mathrm{CaO}$ and high $\mathrm{Fe}_{2} \mathrm{O}_{3}$. Song et al. ${ }^{[32]}$ investigated the effect of coal ash composition on AFTs. According to these authors, AFTs decrease with increasing $\mathrm{CaO}$, $\mathrm{Fe}_{2} \mathrm{O}_{3}$, and $\mathrm{MgO}$ contents, and then increases again after reaching a minimum value. In our own results (Table I), An-4, An-8, Ch-2, Coal-1, and Coal-2 generally had the highest AFTs and these samples also had very low $\mathrm{Fe}_{2} \mathrm{O}_{3}$ contents in comparison to the other samples. Also, Co-5 had the lowest $T_{\text {indef }}$ and $T_{\text {soft }}$ and contained 14.87 pet $\mathrm{Fe}_{2} \mathrm{O}_{3}$, which is fairly high in comparison to the other samples. Additionally, $\mathrm{SiO}_{2}$ seemed higher in the samples with higher AFTs. However, the afore-mentioned observations from our results are somewhat crude and can certainly not be used as the basis for selecting carbonaceous PF to reduce damring formation during chromite pre-reduction. A more systematic approach is required, as there are too many variables and interactions between the variables that need to be taken into consideration. Therefore, MLR was used to establish mathematical relationships between the different factors.

\section{B. Multiple-Linear Regression Analysis to Predict AFTs of Carbonaceous Materials}

In this study, $T_{\text {soft }}$ was considered as the temperature at which PF ash will start contributing to damring formation in the kiln. Therefore, oxidizing $T_{\text {soft }}$ and reducing $T_{\text {soft }}$ were considered as the dependent variables, while the other parameters presented in Table I (excluding the AFTs) were considered as independent parameters in MLR calculations. The relationship between the number of independent variables included in the optimum MLR solutions and the RMSE between the calculated $T_{\text {soft }}$ values and the experimental values (Table I) are presented in Figures 4(a) and (b), for the reducing $T_{\text {soft }}$ and the oxidizing $T_{\text {soft }}$, respectively. As is evident from the results for the reducing $T_{\text {soft }}$ (Figure 4(a)), the RMSE for the optimum MLR equation containing one independent variable was approximately $75 \mathrm{~K}$. This could be reduced to approximately $55 \mathrm{~K}$, if an optimum MLR equation containing two independent variables was calculated. The inclusion of more independent variables in the optimum MLR solution further reduced the RMSE. Additional independent variables were included until the relative improvement ( RMSE for equation with $\mathrm{x}-1$ independent variable - RMSE for equation with $\mathrm{x}$ independent variable)/(RMSE for equation with 1 independent variable - RMSE for equation with all possible independent variables) $\}$ in RMSE was less than 1 pct. For the reducing $T_{\text {soft }}$ (Figure 4(a)), this was found to be a MLR equation containing 10 independent variables for which the RMSE was approximately $1.7 \mathrm{~K}$. In a similar manner, the optimum MLR solution for oxidizing $T_{\text {soft }}$ (Figure 4(b)), which had a relative improvement in RMSE of less than 1 pct (approximately $0.5 \mathrm{~K}$ ), contained 11 
Table I. Proximate and Ultimate Analysis, Total S, Gross CV, Ash Composition, and Reducing and Oxidizing AFT of Materials Considered

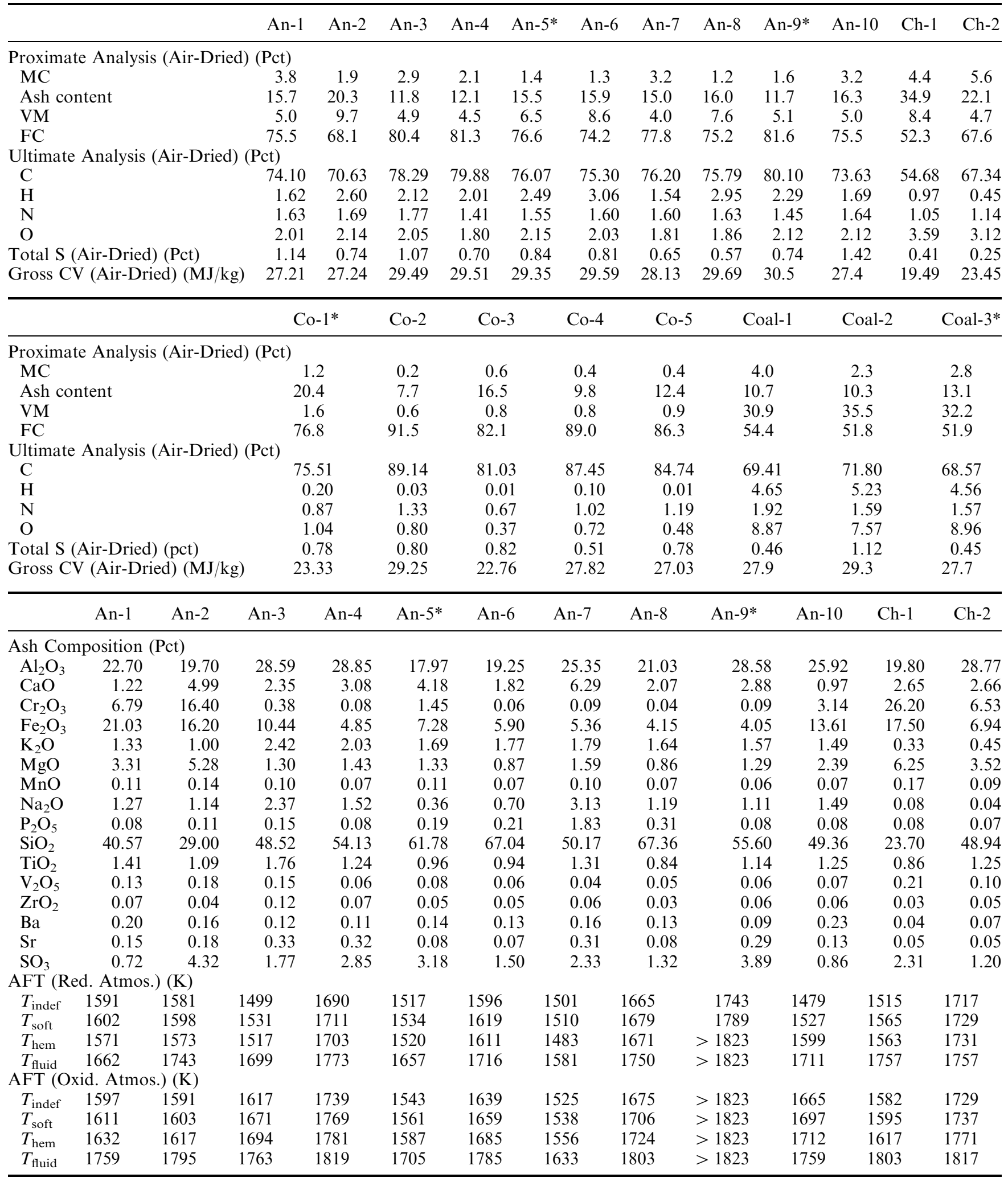


Table I. continued

\begin{tabular}{|c|c|c|c|c|c|c|c|c|}
\hline & $\mathrm{Co}-1^{*}$ & $\mathrm{Co}-2$ & $\mathrm{Co}-3$ & $\mathrm{Co}-4$ & $\mathrm{Co}-5$ & Coal-1 & Coal-2 & Coal-3* \\
\hline \multicolumn{9}{|c|}{ Ash Composition (Pct) } \\
\hline $\mathrm{Al}_{2} \mathrm{O}_{3}$ & 17.41 & 24.88 & 19.77 & 24.89 & 22.42 & 24.39 & 19.23 & 23.59 \\
\hline $\mathrm{CaO}$ & 1.69 & 1.78 & 1.55 & 5.32 & 3.74 & 3.52 & 0.99 & 2.28 \\
\hline $\mathrm{Cr}_{2} \mathrm{O}_{3}$ & 5.64 & 1.79 & 0.88 & 2.20 & 4.57 & 0.44 & 0.44 & 0.13 \\
\hline $\mathrm{Fe}_{2} \mathrm{O}_{3}$ & 12.16 & 17.00 & 9.01 & 15.09 & 14.87 & 3.75 & 5.66 & 2.77 \\
\hline $\mathrm{K}_{2} \mathrm{O}$ & 0.95 & 1.95 & 1.16 & 1.72 & 2.25 & 1.08 & 1.03 & 1.19 \\
\hline $\mathrm{MgO}$ & 1.93 & 1.09 & 0.78 & 3.03 & 2.30 & 1.51 & 0.55 & 1.03 \\
\hline $\mathrm{MnO}$ & 0.16 & 0.12 & 0.12 & 0.20 & 0.13 & 0.02 & 0.08 & 0.01 \\
\hline $\mathrm{Na}_{2} \mathrm{O}$ & 0.09 & 0.92 & 0.11 & 1.37 & 1.25 & 0.27 & 0.22 & 0.16 \\
\hline $\mathrm{P}_{2} \mathrm{O}_{5}$ & 0.17 & 0.33 & 0.21 & 1.11 & 0.29 & 0.27 & 0.11 & 0.09 \\
\hline $\mathrm{SiO}_{2}$ & 57.45 & 48.34 & 63.35 & 40.21 & 46.15 & 59.43 & 68.66 & 65.97 \\
\hline $\mathrm{TiO}_{2}$ & 1.43 & 1.25 & 1.69 & 1.00 & 0.93 & 1.28 & 1.76 & 1.00 \\
\hline $\mathrm{V}_{2} \mathrm{O}_{5}$ & 0.16 & 0.11 & 0.14 & 0.10 & 0.11 & 0.05 & 0.12 & 0.03 \\
\hline $\mathrm{ZrO}_{2}$ & 0.14 & 0.04 & 0.17 & 0.04 & 0.04 & 0.11 & 0.18 & 0.08 \\
\hline $\mathrm{Ba}$ & 0.08 & 0.12 & 0.12 & 0.31 & 0.19 & 0.08 & 0.08 & 0.05 \\
\hline $\mathrm{Sr}$ & 0.04 & 0.11 & 0.06 & 0.19 & 0.11 & 0.11 & 0.05 & 0.04 \\
\hline $\mathrm{SO}_{3}$ & 1.02 & 0.68 & 0.90 & 2.72 & 1.32 & 3.20 & 0.76 & 1.36 \\
\hline \multicolumn{9}{|c|}{ AFT (Red. Atmos.) (K) } \\
\hline$T_{\text {indef }}$ & 1547 & 1463 & 1607 & 1498 & 1409 & 1651 & 1719 & 1727 \\
\hline$T_{\text {soft }}$ & 1593 & 1491 & 1642 & 1517 & 1415 & 1681 & 1739 & 1785 \\
\hline$T_{\text {hem }}$ & 1575 & 1500 & 1639 & 1561 & 1429 & 1662 & 1721 & 1769 \\
\hline$T_{\text {fluid }}$ & 1729 & 1671 & 1729 & 1748 & 1727 & 1735 & 1775 & $>1823$ \\
\hline \multicolumn{9}{|c|}{ AFT (Oxid. Atmos.) (K) } \\
\hline$T_{\text {indef }}$ & 1621 & 1638 & 1652 & 1539 & 1505 & 1736 & 1758 & 1781 \\
\hline$T_{\text {soft }}$ & 1645 & 1651 & 1670 & 1561 & 1541 & 1768 & 1777 & 1817 \\
\hline$T_{\text {hem }}$ & 1654 & 1667 & 1703 & 1651 & 1581 & 1792 & 1798 & $>1823$ \\
\hline$T_{\text {fluid }}$ & 1793 & 1731 & 1777 & 1795 & 1787 & 1822 & 1823 & $>1823$ \\
\hline
\end{tabular}

*These samples were excluded from the MLR calculations but were used to verify the accuracy of the MLR calculations.

independent variables. Considering that the uncertainty associated with AFT measurements is $30 \mathrm{~K}$ (SABS ISO 540:2008), the afore-mentioned RMSE differences between calculated $T_{\text {soft }}$ values and the experimental values (1.7 and $0.5 \mathrm{~K}$, respectively) could be considered which is quantifiable (is associated with a rule) and gave more accurate calculated $T_{\text {soft }}$ values. These two optimized equations for calculating reducing $T_{\text {soft }}$ and oxidizing $T_{\text {soft }}$ are presented in Eqs. [2] and [3], respectively.

$$
\begin{aligned}
&-1.4286 \mathrm{E} 4+(1.7570 \mathrm{E} 2 \times \mathrm{MC})+(1.5738 \mathrm{E} 2 \times \mathrm{Ash})+(1.6621 \mathrm{E} 2 \times \mathrm{C}) \\
&+(2.5337 \mathrm{E} 2 \times \mathrm{H})+(1.3008 \mathrm{E} 2 \times \mathrm{O})+\left(-1.8626 \mathrm{E} 2 \times \mathrm{K}_{2} \mathrm{O}\right)+ \\
& \mathrm{T}_{\text {soft(reducing })}\left(-1.1178 \mathrm{E} 2 \times \mathrm{P}_{2} \mathrm{O}_{5}\right)+\left(-5.0067 \mathrm{E} 2 \times \mathrm{V}_{2} \mathrm{O}_{5}\right)+(7.1129 \mathrm{E} 2 \times \mathrm{Sr})+ \\
&\left(-3.5258 \mathrm{E} 1 \times \mathrm{SO}_{3}\right) \\
& \\
& 2.1568 \mathrm{E} 3+(-2.4588 \mathrm{E} 1 \times \mathrm{MC})+(-5.1311 \mathrm{E} 0 \times \mathrm{FC})+(-3.4287 \mathrm{E} 0 \times \mathrm{H})+ \\
& \mathrm{T}_{\text {soft(oxidizing) }} \begin{array}{l}
\left(1.2248 \mathrm{E} 1 \times \mathrm{Al}_{2} \mathrm{O}_{3}\right)+\left(-1.4721 \mathrm{E} 2 \times \mathrm{K}_{2} \mathrm{O}\right)+(-6.4158 \mathrm{E} 1 \times \mathrm{MgO})+ \\
(1.5306 \mathrm{E} 2 \times \mathrm{MnO})+\left(-1.2579 \mathrm{E} 2 \times \mathrm{P}_{2} \mathrm{O}_{5}\right)+\left(-6.9090 \mathrm{E} 2 \times \mathrm{ZrO}_{2}\right) \\
+
\end{array} \\
&(1.8523 \mathrm{E} 2 \times \mathrm{Ba})+(4.8366 \mathrm{E} 2 \times \mathrm{Sr})
\end{aligned}
$$

as over-fitting of the data. However, the differences in $T_{\text {soft }}$ between the applied rule (1 pct relative improvement in RMSE) and if a $30 \mathrm{~K}$ RMSE limitation was considered were found to be approximately 50 to $100 \mathrm{~K}$ for the $T_{\text {soft }}$. Within the context of industrial application and optimum selection of PF coal, 50 to $100 \mathrm{~K}$ lower/ higher $T_{\text {soft }}$ can have a significant effect on damring formation. Therefore, it was decided to rather implement a relative improvement in RMSE as described,
In order to assess the accuracy of the method, calculated reducing and oxidizing $T_{\text {soft }}$ values were plotted against the experimentally determined values, as indicated in Figures 5(a) and (b), respectively. As mentioned in Section II-B, four samples were not included in the computation of the MLR equation. The $T_{\text {soft }}$ values for these four samples were calculated using the MLR equations obtained. The measured as well as the calculated $T_{\text {soft }}$ values (using Eqs. [2] and [3]) 


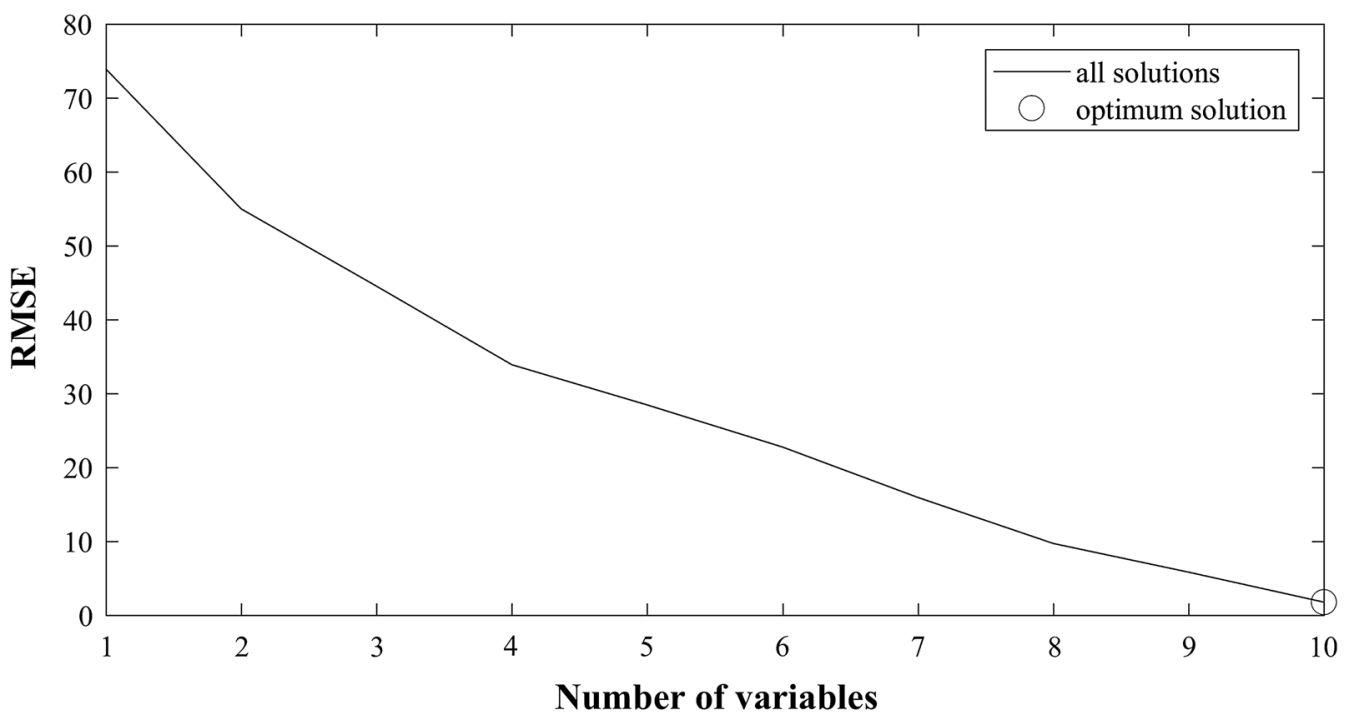

(a)

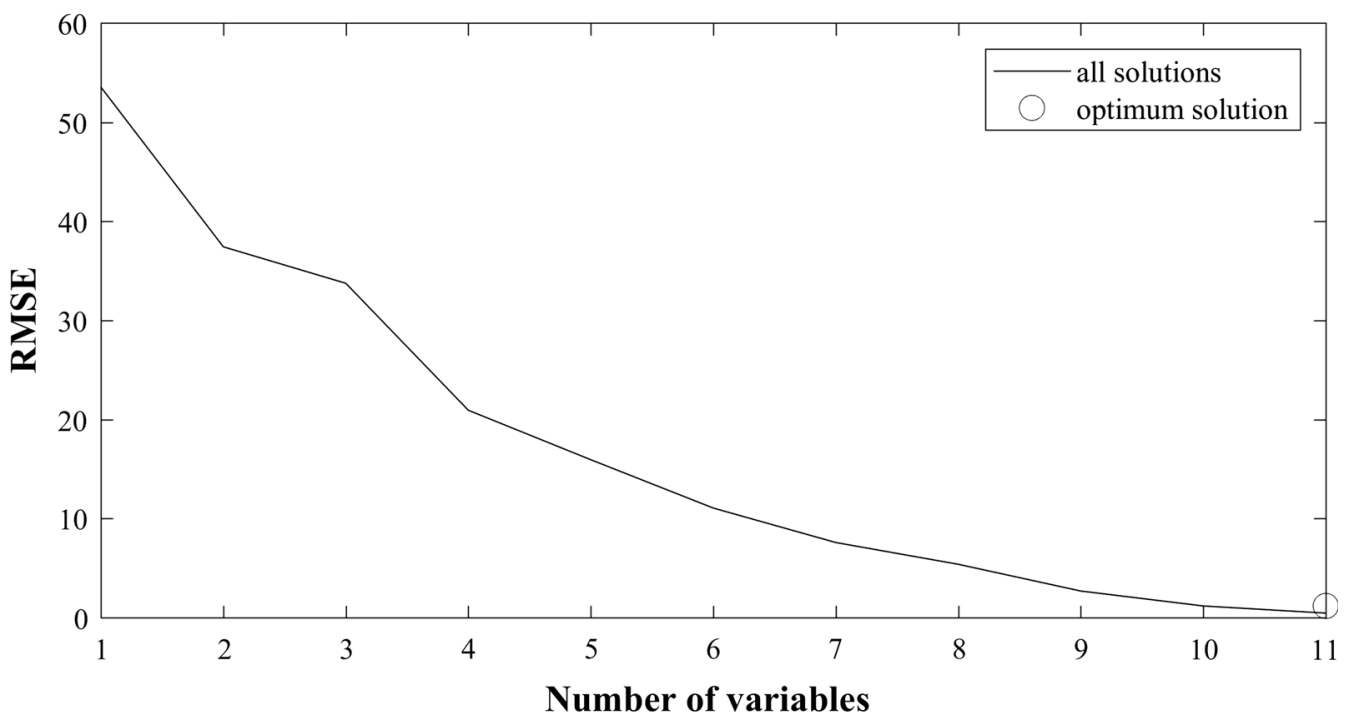

(b)

Fig. 4-RMSE between the calculated and experimental $T_{\text {soft }}$ for reducing $(a)$ and oxidizing $(b)$ atmospheres.

of these samples are shown in Figures 5(a) and (b). An-9 was not included in the MLR calculations because its oxidizing $T_{\text {soft }}$ was above the AFT test limitation of $1823 \mathrm{~K}\left(1550{ }^{\circ} \mathrm{C}\right)$. However, its reducing $T_{\text {soft }}$ value was within the limit and could still be used as an assessment of the accuracy of Eq. [2]. The other three samples that were left out from the MLR calculation (i.e., An-5, Co-1, and Coal-3) were selected randomly to assess both Eqs. [2] and [3].

As is evident from Figure 5(a), the reducing $T_{\text {soft }}$ of the four additional samples (An-9, An-5, Co-1, and Coal-3) compared relatively well with the linear relationship derived from the optimized MLR equation, although two of the values (An-9 and Coal-3) differed by just more than the $30 \mathrm{~K}$ standard deviation associated with AFTs. ${ }^{[19]}$ However, within the context of the absolute values of reducing $T_{\text {soft }}$, which ranged between 1415 and $1789 \mathrm{~K}$, the calculated $T_{\text {soft }}$ of even these samples that did not fit perfectly on the predicted line would still be useful for selecting PF coal better (to reduce damring formation). For the oxidizing $T_{\text {soft }}$ (Figure 5(b)), the values of two of the three additional samples (Co-1 and Coal-3) correlated very well with the linear relationship derived from the MLR calculations, while An-5 was still a good fit if the $30 \mathrm{~K}$ standard deviation $^{[19]}$ is taken into account. The calculated oxidizing $T_{\text {soft }}$ of An-9 (using Eq. [3]) was also added to the figure, even though the experimental value could not be determined.

Chen and Jiang introduced equations cited by Liu et al. ${ }^{[20]}$ that differ from those determined during this study, for predicting oxidizing AFTs of Chinese coal. The method that is suggested in Liu et al. ${ }^{[20]}$ consists of four different equations, with the one that has to be applied selected based on the compositional content of the sample. As a comparison, this method was applied to calculate the oxidizing $T_{\text {soft }}$ of the samples that was left out of the MLR calculations (i.e., An-5, An-9, Co-1, 


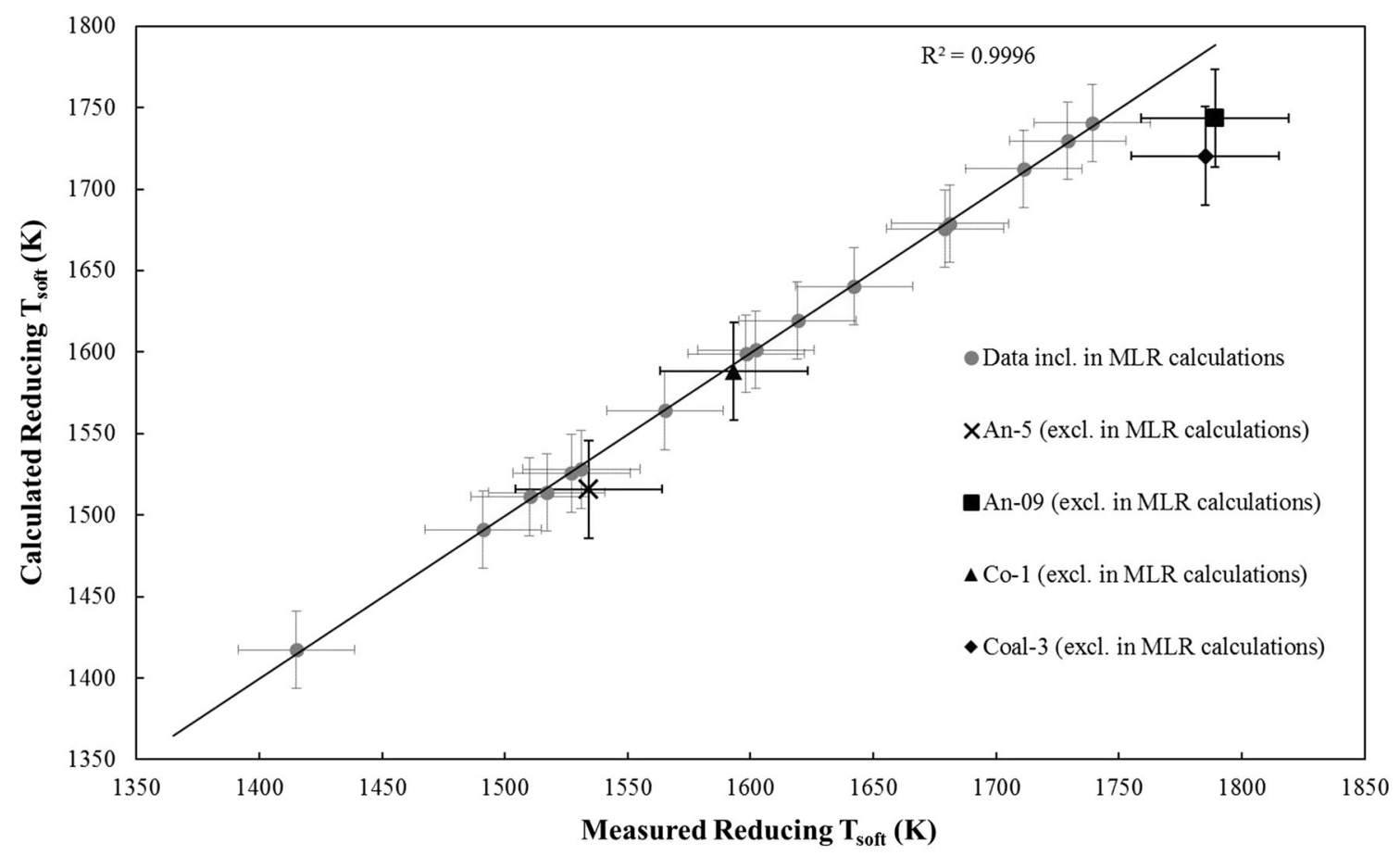

(a)

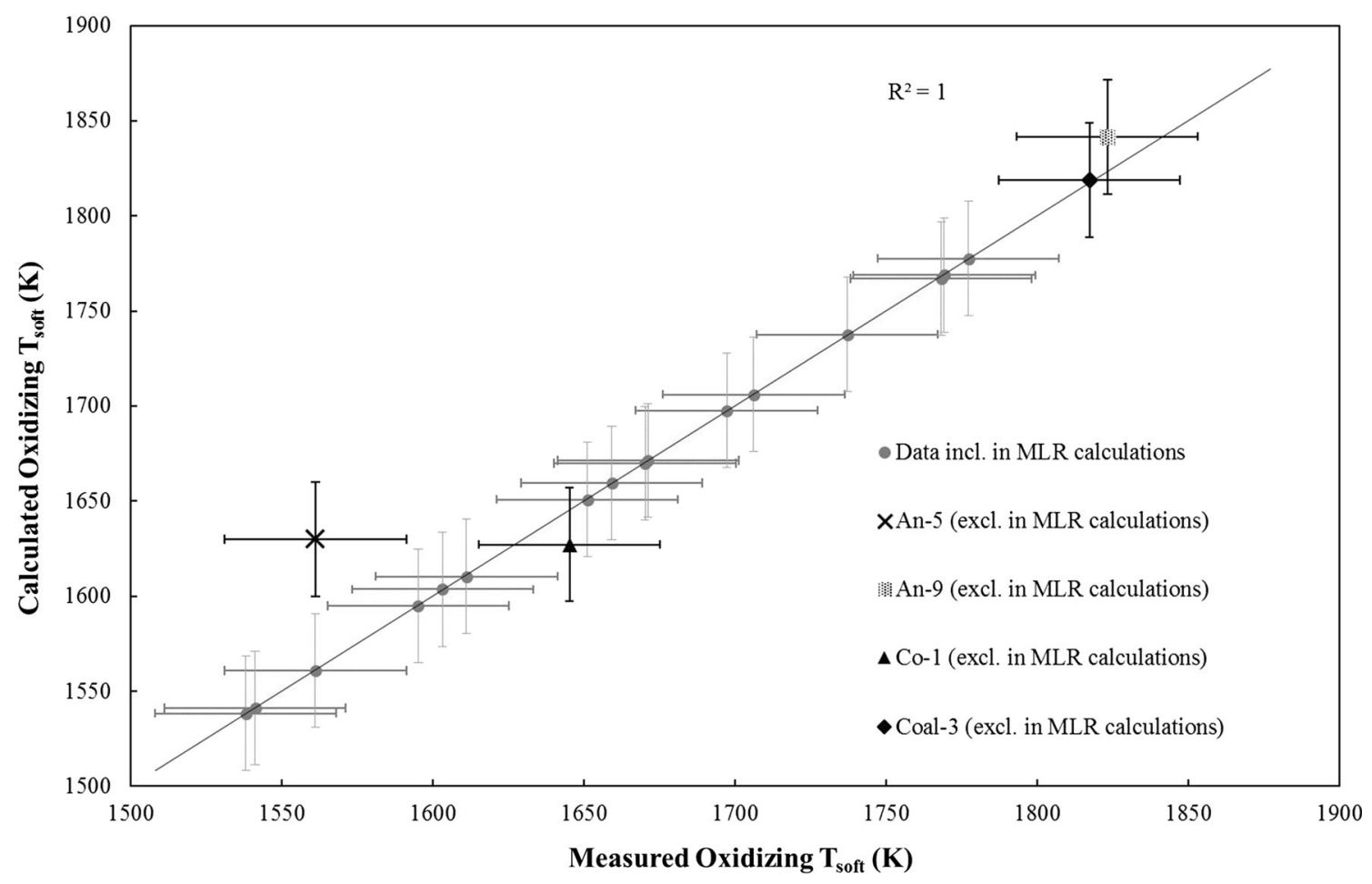

(b)

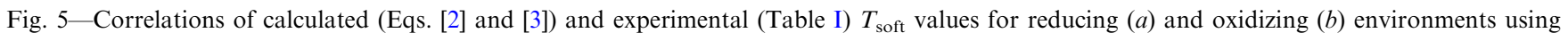
a bivariate correlation method. ${ }^{[33]}$ The error bars indicate the $30 \mathrm{~K}$ standard deviation that is common for AFT measurements.

and Coal-3). Since the equations given by Liu et al. ${ }^{[20]}$ was only for oxidizing $T_{\text {soft }}$, Eq. [3] was used to calculate the $T_{\text {soft }}$ so that the two methods can be compared. The experimental value of the oxidizing $T_{\text {soft }}$ for An-9 is given as $>1823 \mathrm{~K}\left(1550{ }^{\circ} \mathrm{C}\right)$. Using the equation proposed Chen and Jiang as cited by Liu et al..$^{[20]}$ the oxidizing $T_{\text {soft }}$ was calculated as $1710 \mathrm{~K}\left(1437{ }^{\circ} \mathrm{C}\right)$, which is too low. An-5 had an experimental value of $1561 \mathrm{~K}\left(1288^{\circ} \mathrm{C}\right)$ and with the equation in Liu et al. ${ }^{[20]}$ it was calculated as $1575 \mathrm{~K}\left(1303{ }^{\circ} \mathrm{C}\right)$, which is fairly 
accurate. Co-1 and Coal-3 had experimental values of $1654 \mathrm{~K}$ and $1817 \mathrm{~K}\left(1372{ }^{\circ} \mathrm{C}\right.$ and $\left.1544^{\circ} \mathrm{C}\right)$, which were calculated with the Liu et al. ${ }^{[20]}$ equations as $1588 \mathrm{~K}$ and $1721 \mathrm{~K}\left(1315^{\circ} \mathrm{C}\right.$ and $\left.1447^{\circ} \mathrm{C}\right)$, respectively. Even though the calculated values seem to be reasonable, the average error using the equation by Liu et al. ${ }^{[20]}$ is more than 3 pct. Therefore, the equations proposed in this paper seem to enable similar, or even better accuracy, to calculate $T_{\text {soft }}$ than what has been proposed before. The higher accuracy might be due to the inclusion of more independent variables during the determination of the optimum mathematical solution. Our method also only has one equation for calculating oxidizing $T_{\text {soft }}$, which is much simpler than the four equation method proposed by the afore-mentioned authors. $^{[20]}$ Additionally, the equations proposed in the current paper enables calculation of reducing $T_{\text {soft }}$, which has been proven to be important within the application of chromite pre-reduction in rotary kilns. ${ }^{[17]}$

Several authors ${ }^{[34-36]}$ have proposed statistical techniques to calculate parameters that can be used in the interpretation of regression results and to determine the contributions of the different independent variables. For instance, beta weights $(\beta)$ are applied to standardized variable scores in the MLR equation and can be used to interpret independent variable contribution to the regression effect. Structure coefficients $\left(r_{\mathrm{s}}\right)$ are another method that was examined by Kraha et al. ${ }^{[34]}$ Structure coefficients are Pearson correlations between the predicted value given by the regression equation and each independent variable. A squared structure coefficient $\left(r_{\mathrm{s}}^{2}\right)$ gives an indication of the contribution of each independent variable to the variance given by the structure coefficient. A negative $r_{s}$ value show that there is an inverse proportional correlation between the independent variable and the predicted value. Commonality coefficients can also be calculated using the SPSS programming software. Two types of commonality coefficients exist, namely unique and common coefficients. Unique coefficients reveal the amount of variance an independent variable contributes to the MLR equation on its own without sharing its contribution in predicting the dependent variable with other variables. Common coefficients reflect the contribution of an independent variable in combination with one or more independent variables. The commonality coefficients are used to give more information on the covariance between the different independent variables that could not be understood when using $\beta$ weights. ${ }^{[36]}$ According to Lorenzo-Seva et al. ${ }^{[35]}$ relative important weight (RIW) is a measure of the proportionate contribution of each independent variable to $R^{2}$, after correcting for the effects of the intercorrelation among independent variables. The sum of the RIW is equal to $R^{2}$. For the purposes of this paper, the authors mainly focused on the RIW values. All the statistical parameters that were calculated with the SPSS programming software are presented in Table II.

According to RIW values for reducing $T_{\text {soft }}, \mathrm{K}_{2} \mathrm{O}$ content made the largest contribution to the variance, with a value of 20.8 pct. It can also be seen from the commonality coefficients that $\mathrm{K}_{2} \mathrm{O}$ contributed 14.51 pct uniquely to the variance. Other independent values with relatively large RIW values were $\mathrm{H}(20.4 \mathrm{pct}), \mathrm{P}_{2} \mathrm{O}_{5}$ (12.3 pct), $\mathrm{O}$ (11.6 pct), and $\mathrm{V}_{2} \mathrm{O}_{5}(8.9 \mathrm{pct})$. From these results, it can be seen that the intercorrelation between the different variables are very complex and even though the ash components $\left(\mathrm{K}_{2} \mathrm{O}, \mathrm{V}_{2} \mathrm{O}_{5}, \mathrm{P}_{2} \mathrm{O}_{5}\right.$, etc. $)$ contributed significantly to the variance (total of their RIW values $=47.5 \mathrm{pct}$ ), they are not the only determining factor. It was also interesting to note that some ash species such $\mathrm{V}_{2} \mathrm{O}_{5}$ and $\mathrm{Sr}$, which had very low ash compositions (below $0.33 \mathrm{pct}$ ), contributed significantly to the variance ( 8.9 and 4.7 pct RIW, respectively, in Table II). As previously stated, elements occurring in the ash could occur in a different phase as what is presented in the standard ash composition analysis (Table I). To fully understand the impact of individual species and/or combinations of species on the reducing $T_{\text {soft }}$, additional investigations would be required. However, this would make the scope of the current work too extensive. Therefore, deductions from previous investigations were considered. For instance, Wang et al. ${ }^{[37]}$ indicated that $\mathrm{V}_{2} \mathrm{O}_{3}$, rather than $\mathrm{V}_{2} \mathrm{O}_{5}$, is the most likely form of $\mathrm{V}$ in a reducing atmosphere. The melting point of $\mathrm{V}_{2} \mathrm{O}_{3} 2213 \mathrm{~K}$ $\left(1940{ }^{\circ} \mathrm{C}\right)$ is significantly higher than that of $\mathrm{V}_{2} \mathrm{O}_{5} 963 \mathrm{~K}$ $\left(690{ }^{\circ} \mathrm{C}\right),{ }^{[37]}$ which at least partially explaining why the small $\mathrm{V}$ content contributed to a higher $T_{\text {soft }}$.

For the oxidizing $T_{\text {soft }}, \mathrm{P}_{2} \mathrm{O}_{5}$ had the highest RIW value of 18.4 pct. $\mathrm{MnO}$ and $\mathrm{MgO}$ had RIW of 14.3 and 13.2 pct, respectively. Combined the ash components had a RIW contribution of 79.0 pet. Considering the commonality coefficients $\mathrm{P}_{2} \mathrm{O}_{5}$ only contributes 8.8 pct uniquely, but commonly contributed 20.67 pct. $\mathrm{MnO}$ commonly contributed 53.35 pct, while uniquely only 0.11 pet. For the oxidizing $T_{\text {soft }}$, the unique contributions were relatively small. $\mathrm{P}_{2} \mathrm{O}_{5}$ had the largest unique contribution ( 8.8 pct), while all the other variable contributions were less than 5 pct. However, commonly (total of "common" in Table II) the ash components had a large contribution, showing that the interaction between the different ash components played a significant role in predicting AFT for an oxidizing atmosphere.

Detailed ash compositional analyses, which include trace compositions as considered thus far, are not always available to $\mathrm{FeCr}$ producers. Therefore, alternative MLR analyses were also conducted by only considering parameters/species obtained from the most common analyses (i.e., proximate and ultimate analyses, 
Table II. Statistical Parameters that Were Calculated with SPSS Software for the Interpretation of Regression Results and to Determine the Contributions of the Different Independent Variables to the Calculated AFTs

\begin{tabular}{|c|c|c|c|c|c|c|}
\hline Variable & $\beta$ & $r_{\mathrm{s}} \cong r$ & $\left(r_{\mathrm{s}}\right)^{2} \cong R_{\mathrm{yx}}^{2}$ & Unique & Common & RIW (Pct) \\
\hline \multicolumn{7}{|c|}{ Red Soft Temp } \\
\hline $\mathrm{MC}$ & 2.943 & 0.364 & 0.1325 & 0.1134 & 0.0191 & 5.3 \\
\hline Ash & 10.486 & 0.098 & 0.0097 & 0.1808 & -0.1712 & 7.1 \\
\hline $\mathrm{C}$ & 14.367 & 0.41 & 0.1677 & 0.1847 & -0.0169 & 8.1 \\
\hline $\mathrm{H}$ & 4.231 & 0.568 & 0.3222 & 0.2075 & 0.1148 & 20.4 \\
\hline $\mathrm{O}$ & 3.168 & 0.552 & 0.3037 & 0.1516 & 0.1521 & 11.6 \\
\hline $\mathrm{K}_{2} \mathrm{O}$ & -1.138 & 0.504 & 0.2532 & 0.1451 & 0.1082 & 20.8 \\
\hline $\mathrm{P}_{2} \mathrm{O}_{5}$ & 0.556 & 0.385 & 0.1477 & 0.1481 & -0.0004 & 12.3 \\
\hline $\mathrm{V}_{2} \mathrm{O}_{5}$ & 0.263 & 0.161 & 0.0258 & 0.0197 & 0.006 & 8.9 \\
\hline $\mathrm{Sr}$ & 0.707 & 0.257 & 0.0658 & 0.0502 & 0.0156 & 4.7 \\
\hline $\mathrm{SO}_{3}$ & -0.389 & 0.039 & 0.0015 & 0.0465 & -0.0449 & 0.8 \\
\hline \multicolumn{7}{|c|}{ Ox Soft Temp } \\
\hline $\mathrm{MC}$ & -0.476 & 0.269 & 0.0724 & 0.0265 & 0.0459 & 3.4 \\
\hline $\mathrm{FC}$ & -0.81 & -0.409 & 0.1673 & 0.0125 & 0.1548 & 6.5 \\
\hline $\mathrm{H}$ & -0.084 & 0.576 & 0.3323 & 0.0003 & 0.332 & 11 \\
\hline $\mathrm{Al}_{2} \mathrm{O}_{3}$ & 0.516 & 0.199 & 0.0397 & 0.0484 & -0.0087 & 10.1 \\
\hline $\mathrm{K}_{2} \mathrm{O}$ & -1.122 & 0.208 & 0.0432 & 0.1107 & -0.0675 & 7.6 \\
\hline $\mathrm{MgO}$ & -1.379 & -0.417 & 0.1741 & 0.0448 & 0.1293 & 13.2 \\
\hline $\mathrm{MnO}$ & 0.097 & -0.731 & 0.5346 & 0.0011 & 0.5335 & 14.3 \\
\hline $\mathrm{P}_{2} \mathrm{O}_{5}$ & -0.768 & -0.543 & 0.2951 & 0.0883 & 0.2067 & 18.4 \\
\hline $\mathrm{ZrO}_{2}$ & -0.416 & 0.481 & 0.2312 & 0.0191 & 0.212 & 5.9 \\
\hline $\mathrm{Ba}$ & 0.189 & -0.524 & 0.2741 & 0.006 & 0.2681 & 6.2 \\
\hline $\mathrm{Sr}$ & 0.615 & -0.185 & 0.0341 & 0.0207 & 0.0133 & 3.5 \\
\hline
\end{tabular}

$\mathrm{CV}$, as well as $\mathrm{S}$ and $\mathrm{P}$ contents) as independent parameters. Such optimized MLR equations are indicated in Eqs. [4] and [5]. (c) start of reduction, when the first gas bubbles were evolved from the sample. None of the afore-mentioned temperatures can be directly correlated with the $T_{\text {soft }}$

$$
\begin{aligned}
& 5.1644 \mathrm{E} 4+(-4.4774 \mathrm{E} 2 \times \mathrm{MC})+(-5.0252 \mathrm{E} 2 \times \mathrm{Ash})+(-5.7204 \mathrm{E} 2 \times \mathrm{S})+ \\
\mathrm{T}_{\text {soft }(\text { reducing })=} & (-4.9658 \mathrm{E} 2 \times \mathrm{C})+(-3.8675 \mathrm{E} 2 \times \mathrm{H})+(-8.2477 \mathrm{E} 2 \times \mathrm{N}) \\
& +(-5.2977 \mathrm{E} 2 \times \mathrm{O}) \\
& 4.9162 \mathrm{E} 4+(-4.7869 \mathrm{E} 2 \times \mathrm{MC})+(-4.7767 \mathrm{E} 2 \times \mathrm{Ash})+(-4.0485 \mathrm{E} 2 \times \mathrm{VM})+ \\
\mathrm{T}_{\text {soft }(\text { oxidizing })=} & (-3.7872 \mathrm{E} 2 \times \mathrm{FC})+(8.1854 \mathrm{E} 0 \times \mathrm{CV})+(-9.6356 \mathrm{E} 1 \times \mathrm{C})+ \\
& (-4.1131 \mathrm{E} 2 \times \mathrm{N})
\end{aligned}
$$

The above-mentioned optimized MLR equations had RMSE differences between the calculated and experimental reducing and oxidizing $T_{\text {soft }}$ of 39.3 and $41.4 \mathrm{~K}$, respectively. Therefore, these values are less accurate than those calculated with Eqs. [2] and [3]; however, they are still very useful as coarse-grained estimates of reducing and oxidizing $T_{\text {soft }}$.

\section{Sessile Drop Analysis of Chromite, Composite Pellet Mixtures, and Pellet Components}

Ringdalen et al. ${ }^{[24]}$ used three points to define different stages of melting and/or reduction of manganese ores during sessile drop tests, i.e. (a) initiation of melting that is defined as the temperature at which liquid became visible on the surface of the ore; (b) completion of melting, when the ore appeared to be completely liquid; determined with AFT, which was used in Section III-B as a possible indication of the initiation of damring formation. Therefore, for the purpose of this study it was decided to consider the sessile drop test temperature at which any sign of deformation occurred, as an indication of possible damring formation. This can be in the form of bubbling, lifting, movement, rounding of corners, etc. Figures 6, 7, and 8 present example images of how deformation was detected during the sessile drop tests for ores, composite pellet mixtures, and the bentonite clay, respectively.

Table III presents the deformation temperatures derived from the sessile drop tests for all the samples considered. There are several important deductions that can be made from these results, within the context of this paper. The deformation temperatures of all the ores ranged between $1738 \mathrm{~K}$ and $2029 \mathrm{~K}\left(1465{ }^{\circ} \mathrm{C}\right.$ and 


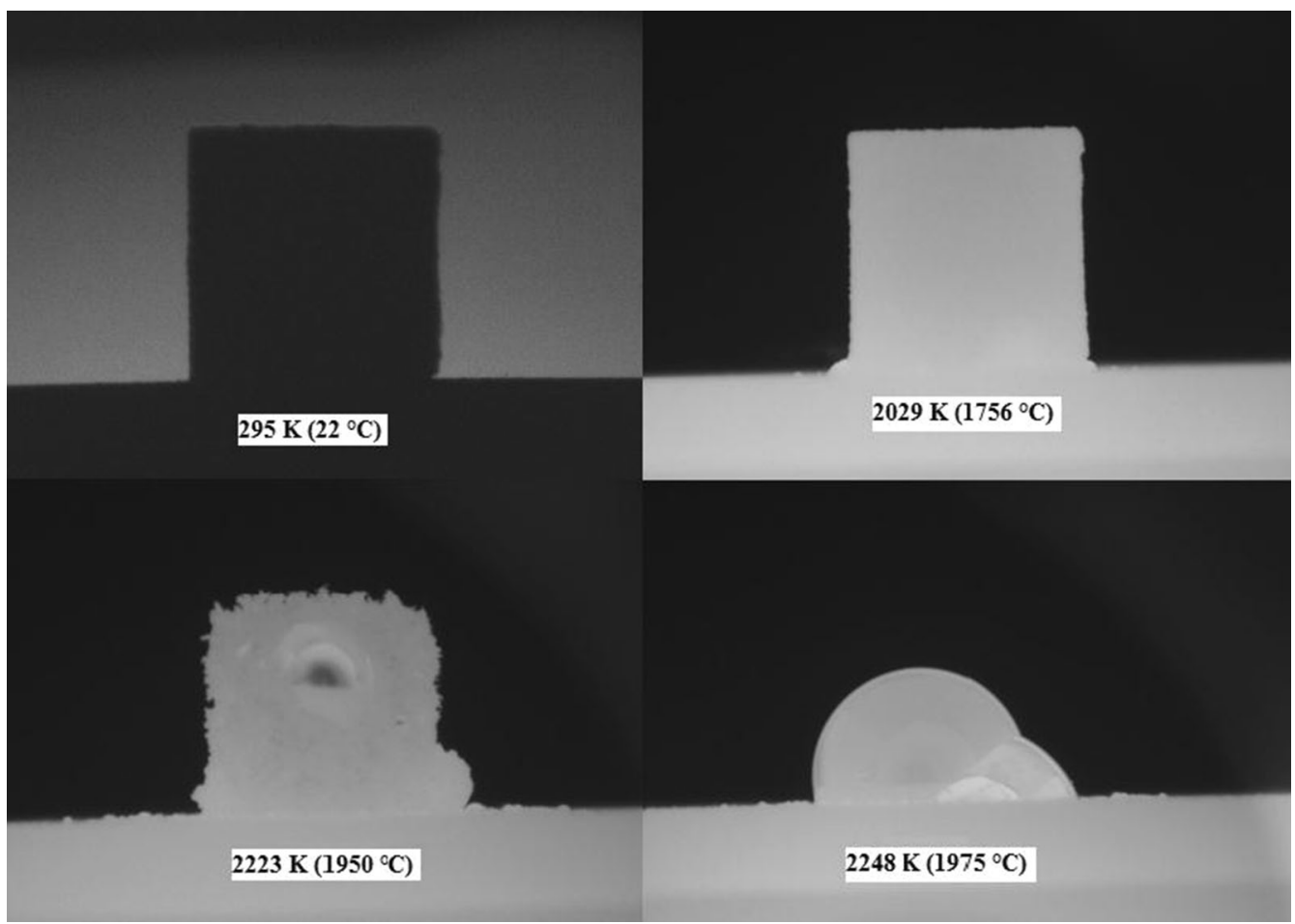

Fig. 6-Sessile drop test images of Kroondal metallurgical grade chromite ore. The first sign of deformation was visible at $2029 \mathrm{~K}\left(1756{ }^{\circ} \mathrm{C}\right)$ in the form of softening of the pellet bottom. At $2223 \mathrm{~K}\left(1950^{\circ} \mathrm{C}\right)$, the sample continued to soften to the point where it was considered to be melted, which was at $2248 \mathrm{~K}\left(1975^{\circ} \mathrm{C}\right)$, at which point the sample took a spherical shape.

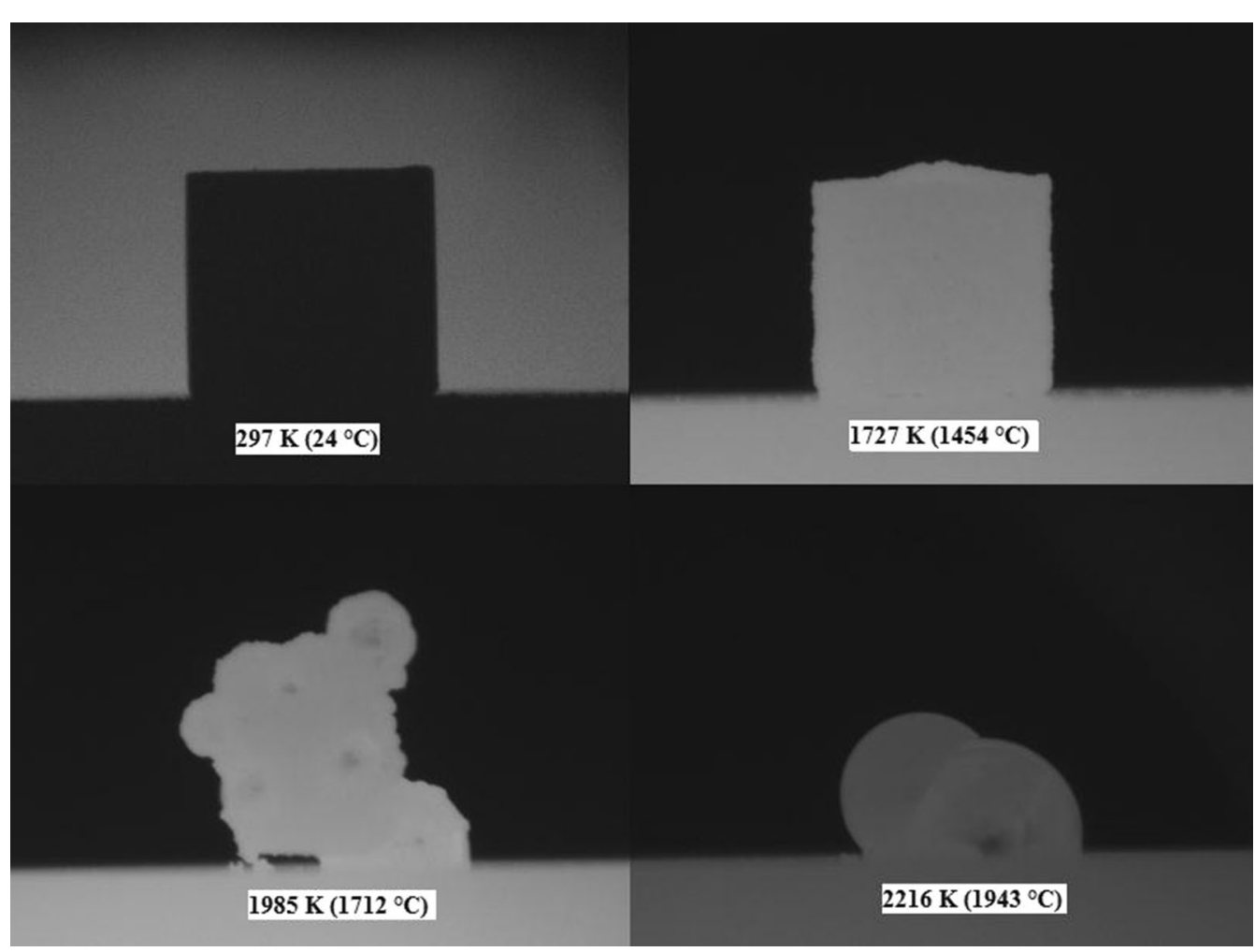

Fig. 7-Sessile drop test images of composite pellet mixture (containing Kroondal metallurgical grade ore). The first sign of deformation occurred at $1727 \mathrm{~K}\left(1454{ }^{\circ} \mathrm{C}\right)$. The sample continued to deform as can be seen at $1985 \mathrm{~K}\left(1712{ }^{\circ} \mathrm{C}\right)$ until the melting point was reached where the sample took a spherical shape, which was at $2216 \mathrm{~K}\left(1943^{\circ} \mathrm{C}\right)$. 


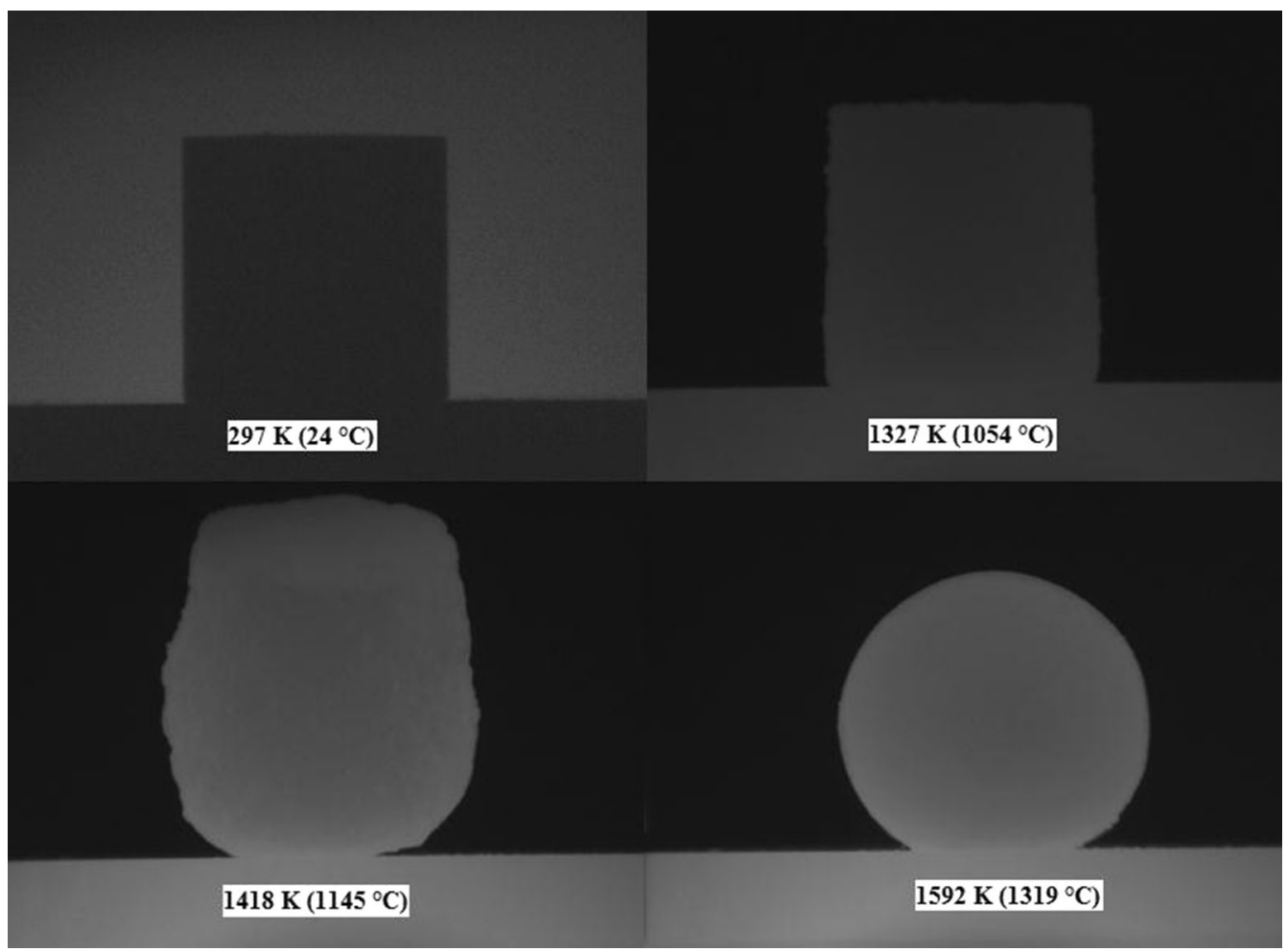

Fig. 8- Sessile drop test images of bentonite clay. The clay started swelling at $1327 \mathrm{~K}\left(1054{ }^{\circ} \mathrm{C}\right)$, at $1418 \mathrm{~K}\left(1145^{\circ} \mathrm{C}\right)$ the edges started rounding, and at $1592 \mathrm{~K}\left(1319^{\circ} \mathrm{C}\right)$ the sample was completely melted as it took a spherical shape.

Table III. Temperatures of Deformation of the Different Ores, Composite Pellet Mixtures, and Pellet Components According to the Sessile Drop Tests

\begin{tabular}{lll}
\hline & First Point of Deformation & Description \\
\hline Ore & & lifting at bottom left corner \\
DRB ECD & 1951 & bottom lifting up \\
DRB MetC & 1773 & bottom right corner lifting up \\
Helena & 1843 & bottom left corner softening \\
Kroondal & 2029 & bubble on right upper corner \\
MMG & 1739 & bubbling at the top \\
UG2 & 1917 & lifting at bottom left corner \\
TWF & 1901 & \\
Pellet Ore Mixtures & & small bubble in middle \\
DRB ECD mix & 1739 & bubble on left \\
DRB met conc mix & 1712 & lifting at the bottom \\
Helena mix & 1689 & lifting at the top \\
Kroondal mix & 1727 & bubbles on top and left \\
MMG mix & 1730 & lifting \\
UG2 mix & 1734 & lifting at the right corner \\
TWF mix & 1646 & bubbling on the left side \\
Nkomati anthracite & 1519 & bubbling edges \\
Clay & 1328 &
\end{tabular}

$\left.1756{ }^{\circ} \mathrm{C}\right)$, which are significantly higher than the typical maximum temperature of the pellets being pre-reduced in a chromite pre-reduction rotary kiln, i.e., $1573 \mathrm{~K}$ $\left(1300^{\circ} \mathrm{C}\right)$. It is therefore unlikely that the ores alone will contribute to damring formation. The composite pellet mixtures had significantly lower deformation temperatures, which ranged from $1646 \mathrm{~K}$ to $1739 \mathrm{~K}\left(1373{ }^{\circ} \mathrm{C}\right.$ to
$1466{ }^{\circ} \mathrm{C}$ ), than the ores alone. However, these temperatures were still above the typical maximum pellet pre-reduction temperature. Therefore, limited contribution to damring formation can be expected from composite pellets. Fragmentation of composite pellets (pellet breakdown) due to various reasons (e.g., too high moisture content of green pellets, too fast heating in 
heating chambers prior to rotary kiln) can release small amounts of reductants and/or clay which can contribute to damring formation, since the deformation temperatures of these materials were $1529 \mathrm{~K}$ and $1327 \mathrm{~K}$ $\left(1256^{\circ} \mathrm{C}\right.$ and $\left.1054{ }^{\circ} \mathrm{C}\right)$, respectively. The UG2 ore and the UG2 containing composite pellet mixture did not have the lowest deformation temperatures, when compared with the other metallurgical grade chromite ores and the correlating composite pellet mixtures. The commonly held industry perception that UG2 ore will lead to quicker and/or more excessive damring formation is therefore not true.

\section{Surface Analysis of Damrings}

In order to augment the results derived from the AFT and sessile drop tests, and associated statistical processing thereof, actual damrings were also considered. Several damring fragments that were broken out of a pre-reduction kiln during a shutdown were polished without the addition of resin to avoid carbon contamination and examined with SEM-EDS. In Figure 9, a SEM micrograph of a cross-sectional polished representative specimen is presented. From this micrograph, it is evident that the damrings

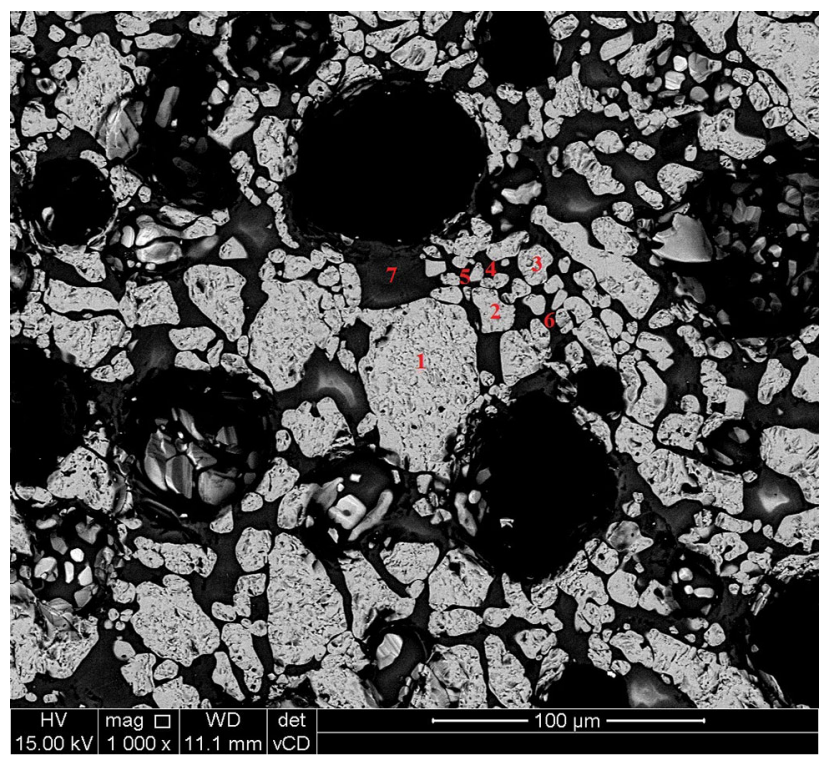

Fig. 9-SEM micrograph of a polished section of damring fragment broken out of a chromite pre-reduction rotary kiln. Numbers 1 to 7 indicate areas that were analyzed with EDS. consisted of lighter colored particles (elements with higher atomic numbers) that are bonded together with a darker colored matrix (elements with lower atomic numbers). Average EDS analyses of the lighter colored particles (points 1, 2, and 3 in Figure 9) and darker areas (points 4, 5, 6, and 7) are indicated in Table IV. From these results, it can be deducted that the lighter colored particles are mainly pellet fragments, since the $\mathrm{Cr}$ (24.6 wt pct) and $\mathrm{Fe}(16.0 \mathrm{wt}$ pct) contents, and $\mathrm{Cr} /$ Fe ratio (1.54) resembled typical South African metallurgical grade chromite ore. ${ }^{[3]}$ The small amount of $\mathrm{C}$ present in these particle can possibly originate from the carbon reductant included in the composite pellet mixture. This $\mathrm{C}$ can be present as free $\mathrm{C}$ or as part of metal carbides that form during pre-reduction. In contrast, the darker matrix, which surrounded the afore-mentioned pellet fragments, only contained trace amounts of $\mathrm{Cr}$ and $\mathrm{Fe}$. However, this matrix contained a significant amount of $\mathrm{Si}$ that is the most prevalent $\mathrm{PF}$ coal ash element (Table I). Also, this darker matrix contained very high concentrations of $\mathrm{C}$, which is indicative of unburned PF coal. Such high $\mathrm{C}$ contents will not be possible if the matrix was dominated by the clay binder and/or the gangue minerals included in the composite pellets.

\section{CONCLUSIONS}

As far as the authors could assess, this is the first study published in the peer-reviewed public domain that assesses the possible contribution of carbonaceous PF ash, chromite ore, as well as composite pellet mixtures to damring formation in chromite pre-reduction rotary kilns.

It was proven that the oxidizing and reducing AFTs of some carbonaceous PF were below the typical maximum temperature of pre-reduced pellets in a chromite pre-reduction process, i.e., $1573 \mathrm{~K}\left(1300^{\circ} \mathrm{C}\right)$. However, for the pellets to be heated to approximately $1573 \mathrm{~K}\left(1300^{\circ} \mathrm{C}\right)$, the actual PF flame temperature must be significantly higher. Therefore, PF ash was identified as the most likely source of damring formation. This does not imply that damrings consist exclusively of $\mathrm{PF}$ ash. In reality, damrings contain $>30$ wt pet $\mathrm{Cr}_{2} \mathrm{O}_{3}$. This significant $\mathrm{Cr}$ content, combined with the afore-mentioned result, implies that the PF ash is the "glue" that binds chromite particles originating from composite pellet fragments and/or disintegrated pellets together. However, the different carbonaceous materials evaluated in this study had significantly different AFTs.

Table IV. Average EDS Analyses (Weight Percent) of Lighter (Areas 1, 2, and 3) and Darker Areas (Areas 4, 5, 6, and 7) in the Micrograph (Figure 9) of a Cross-Sectional Polished Damring Fragment

\begin{tabular}{|c|c|c|c|c|c|c|c|c|c|c|c|c|c|}
\hline Areas & $\mathrm{C}$ & $\mathrm{O}$ & $\mathrm{Na}$ & $\mathrm{Mg}$ & $\mathrm{Al}$ & $\mathrm{Si}$ & $\mathrm{K}$ & $\mathrm{Ca}$ & $\mathrm{Ti}$ & V & $\mathrm{Cr}$ & $\mathrm{Fe}$ & Total \\
\hline $1,2,3$ & 8.28 & 39.41 & & 5.04 & 6.5 & 0.26 & & & & & 24.58 & 15.92 & 100 \\
\hline $4,5,6,7$ & 36.73 & 42.5 & 0.15 & 0.54 & 3.21 & 13.84 & 0.28 & 0.91 & 0.56 & 0.18 & 0.16 & 0.96 & 100 \\
\hline
\end{tabular}


Therefore, if ferrochrome producers want to limit damring formation, AFTs have to be specified as selection criteria for procurement of PF. Currently, only proximate analyses and cost considerations are used to select PFs. If determining AFTs is not practical, the MLR equations (Eqs. [2] and [3]) derived in this study can be used to estimate the oxidizing and reducing $T_{\text {soft }}$. An important future prospective would be to investigate the influence of independent variables included in the afore-mentioned optimum MLR equations, as well as the interaction between species and ash species with the clay binder and the silicate gangue.

Sessile drop tests proved that chromite ores will not contribute significantly to damring formation. Composite pellet mixtures, containing both a carbonaceous reductant and a clay binder, had lower deformation temperatures than the ores alone. However, these deformation temperatures were still above the typical maximum temperature of pre-reduced pellets in a chromite pre-reduction process. Therefore, limited contribution to damring formation is expected from composite pellets. However, pellet fragmentation could release carbonaceous reductant ash and clay binder particles, both of which had much lower deformation temperatures. It was also proven that UG2 ore does not necessarily contribute more to damring formation than metallurgical grade chromite ore. Each ore and composite pellet mixture has to be evaluated separately to assess its possible contribution to damring formation.

SEM-EDS analyses of actual damrings proved that the damrings consisted of chromite pellet fragments, which were bonded together with a matrix mainly originating from the PF coal ash, which supported the earlier conclusions.

\section{ACKNOWLEDGMENTS}

The financial assistance of the National Research Foundation (NRF) toward the PhD studies of Y. van Staden is hereby acknowledged. Opinions expressed and conclusions arrived at are those of the authors and are not necessarily to be attributed to the NRF. The authors would also like to acknowledge the South African Research Chairs Initiative of the Department of Science and Technology (Coal Research Chair Grant No. 86880) for financial support provided for material characterization analyses. The support from the Norwegian Research Council through the project "Metal production - education, competence and research" (261692/H30) is also acknowledged for encouraging and funding cooperation between South Africa and Norway, as well as funding from the Research Project 233825/E30 CORALSEA (Chrome Oxide Reduction - an Atomic Level modelling and Spectrographic Experimental Approach) and by the SFI Metal Production (Centre for Research-based Innovation, 237738).

\section{OPEN ACCESS}

This article is distributed under the terms of the Creative Commons Attribution 4.0 International License (http://creativecommons.org/licenses/by/4.0/), which permits unrestricted use, distribution, and reproduction in any medium, provided you give appropriate credit to the original author(s) and the source, provide a link to the Creative Commons license, and indicate if changes were made.

\section{REFERENCES}

1. S.E. Haggerty: Rev. Miner. Geochem., 1991, vol. 25, pp. 355416.

2. M. Riekkola-Vanhanen: Finnish Expert Report on Best Available Techniques in Ferrochromium Production, Helsinki, 1986.

3. Y.R. Murthy, S.K. Tripathy, and C.R. Kumar: Miner. Eng., 2011, vol. 24, pp. 375-80. https://doi.org/10.1016/j.mineng.2010.12.001.

4. D.S. Rao, S.I. Angadi, S.D. Muduli, and B.D. Nayak: At Miner. Process. Eng. Ed., 2010, vol. 51, pp. 2-6.

5. J. Daavittila, M. Honkaniemi, and P. Jokinen: J. S. Afr. Inst. Min. Metall., 2004, vol. 104, pp. 514-49.

6. W. Biermann, R.D. Cromarty, and N.F. Dawson: J. S. Afr. Inst. Min. Metall., 2012, vol. 12, pp. 301-08.

7. O. Naiker and T. Riley: Proceedings of the Southern African Pyrometallurgy Conference, Johannesburg, South Africa, March 2006, pp. 297-306.

8. C. Takano, A.P. Zambrano, A.E.A. Nogueira, M.B. Mourao, and Y. Iguchi: ISIJ Int., 2007, vol. 47, pp. 1585-89. https://doi.org/ 10.2355/isijinternational.47.1585.

9. S. McCullough, S. Hockaday, C. Johnson, and N.A. Barcza: Proceedings of 12th International Ferroalloys Congress, Helsinki, June 2010, pp. 249-62.

10. O. Naiker: Proceedings of 11th International Ferroalloys Congress, New Delhi, India, February 2007, pp. 112-19.

11. J.P. Beukes, S.P. Du Preez, P.G. van Zyl, D. Paktunc, T. Fabritius, M. Päätalo, and M. Cramer: J. Cleaner Prod., 2017, vol. 165, pp. 874-89. https://doi.org/10.1016/j.jclepro.2017.07.176.

12. G.T.M. Mohale, J.P. Beukes, E.L.J. Kleynhans, P.G. van Zyl, J.R. Bunt, L.R. Tiedt, A.D. Venter, and A. Jordaan: J. S. Afr. Inst. Min. Metall., 2017, vol. 117, pp. 1045-52. https://doi.org/ 10.17159/2411-9717/2017/v117n11a9.

13. N.F. Dawson and R.I. Edwards: Proceedings of 4th International Ferroalloys Congress, Sao Paulo, Brazil, August 1986, pp. 105-13.

14. R.C. Nunnington and N.A. Barcza: Proceedings of 5th International Ferroalloys Congress, New Orleans, USA, March 1989, pp. $55-68$.

15. P. Weber and R.H. Eric: Miner. Eng., 2006, vol. 19, pp. 318-24. https://doi.org/10.1016/j.mineng.2005.07.010.

16. B. Neizel, J.P. Beukes, P.G. Van Zyl, and N.F. Dawson: Miner. Eng., 2013, vol. 45, pp. 115-20. https://doi.org/10.1016/j.mineng. 2013.02.015.

17. E.L.J. Kleynhans, J.P. Beukes, P.G. Van Zyl, P.H.I. Kestens, and J.M. Langa: Miner. Eng., 2012, vol. 34, pp. 55-62. https://doi.org/ 10.1016/j.mineng.2012.03.021.

18. E.L.J. Kleynhans, J.P. Beukes, P.G. van Zyl, R.J. Bunt, N.S.B. Nkosi, and M. Venter: Metall. Mater. Trans. B, 2017, vol. 48, pp. 827-40. https://doi.org/10.1007/s11663-016-0878-4.

19. M.V. Nel, C.A. Strydom, H. Schobert, J.P. Beukes, and J.R. Bunt: Fuel Process. Technol., 2014, vol. 124, pp. 78-86. https://doi.org/ 10.1016/j.fuproc.2014.02.014

20. Y.P. Liu, M.G. Wu, and J.X. Qian: Thermochim. Acta, 2007, vol. 454, pp. 64-68. https://doi.org/10.1016/j.tca.2006.10.026.

21. S. Chakravarty, A. Mohanty, A. Banerjee, R. Tripathy, G.K. Mandal, M.R. Basariya, and M. Sharma: Fuel, 2015, vol. 150, pp. 96-101. https://doi.org/10.1016/j.fuel.2015.02.015.

22. E.C. Winegartner and B.T. Rhodes: J. Eng. Power., 1975, vol. 97, pp. 395-406. https://doi.org/10.1115/1.3446018. 
23. S. Gaal, D. Lou, S. Wasbø, B. Ravaray and M. Tangstad: Proceedings of 11th International Ferroalloys Congress, New Delhi, India, February 2007, pp. 247-57.

24. E. Ringdalen, S. Gaal, M. Tangstad, and O. Ostrovski: Metall. Trans. B, 2010, vol. 41B, pp. 1220-29. https://doi.org/10.1007/ s11663-010-9350-z.

25. J. Safarian, L. Kolbeinsen, M. Tangstad, and G. Tranell: Metall. Trans. B, 2009, vol. 40B, pp. 929-39. https://doi.org/10.1007/ 11663-009-9294-3.

26. S.P. Du Preez, J.P. Beukes, and P.G. Van Zyl: Metall. Mater. Trans. B, 2015, vol. 46, pp. 1002-10. https://doi.org/10.1007/ s11663-014-0244-3.

27. A.D. Venter, J.P. Beukes, P.G. Van Zyl, E.G. Brunke, C. Labuschagne, F. Slemr, R. Ebinghaus, and H. Kock: Atmos. Chem. Phys., 2015, vol. 15, pp. 10271-80. https://doi.org/10.5194 acp-15-10271-2015.

28. N.R. Awang, N.A. Ramli, A.S. Yahaya, and M. Elbayoumi: Atmos. Pollut. Res., 2015, vol. 6, pp. 726-34. https://doi.org/10.5094/ APR.2015.081.

29. E.L.J. Kleynhans, B.W. Neizel, J.P. Beukes, and P.G. Van Zyl: Miner. Eng., 2016, vol. 92, pp. 114-24. https://doi.org/10.1016/ j.mineng.2016.03.005.
30. Sentula mining: Nkomati Anthracite (Pty) Ltd, http://www.sentu la.co.za/?page_id=28, accessed 15 Aug 2017.

31. J.C. van Dyk and M.J. Keyser: J. S. Afr. Inst. Min. Metall., 2005, vol. 105 , pp. $1-6$.

32. W.J. Song, L.H. Tang, X.D. Zhu, Y.Q. Wu, Z.B. Zhu, and S. Koyama: Energy Fuels, 2009, vol. 24, pp. 182-89. https://doi.org/ $10.1021 / \mathrm{ef} 800974 \mathrm{~d}$.

33. K. Thirumalai, A. Singh, and R. Ramesh: J. Geol. Soc. India, 2011, vol. 77, pp. 377-80. https://doi.org/10.1007/s12594-0110044-1.

34. A. Kraha, H. Turner, K. Nimon, L.R. Zientek, and R.K. Henson: Front. Psychol., 2012, vol. 3, pp. 1-16. https://doi.org/10.3389/ fpsyg.2012.00044.

35. U. Lorenzo-Seva, P.J. Ferrando, and E. Chico: Behav. ResMethods, 2010, vol. 42, pp. 29-35. https://doi.org/10.3758/BRM. 42.1.29.

36. L.L. Nathans, F.L. Oswald, and K. Nimon: Pract. Assess. Res. Eval., 2012, vol. 17, pp. 1-19.

37. Z. Wang, J. Bai, L. Kong, Z. Bai, and W. Li: Energy Fuels, 2013, vol. 27, pp. 7303-13. https://doi.org/10.1021/ef401651w.

38. L.A. Cramer, J. Basson, and L.R. Nelson: J. S. Afr. Inst. Min. Metall., 2004, vol. 104, pp. 517-27. 